\title{
Color Removal from Wastewater using a Synthetic High Performance Antifouling GO-CPTMS@Pd- TKHPP/Polyether Sulfone Nanofiltration Membrane
}

foad gholami

Razi University of Kermanshah: Razi University

sirus zinadini ( $\square$ sirus.zeinaddini@gmail.com )

Razi University of Kermanshah: Razi University

Soheila Nakhjiri Kamrani

Razi University of Kermanshah: Razi University

ali akbar zinatizadeh

Razi University of Kermanshah: Razi University

Kiumars Bahrami

Razi University of Kermanshah: Razi University

\section{Research Article}

Keywords: Polyether sulfone, nanofiltration membrane, anti-fouling property, modified graphene oxide, dye removal, wastewater treatment

Posted Date: June 24th, 2021

DOI: https://doi.org/10.21203/rs.3.rs-552481/v1

License: (c) (1) This work is licensed under a Creative Commons Attribution 4.0 International License. Read Full License

Version of Record: A version of this preprint was published at Environmental Science and Pollution Research on November 5th, 2021. See the published version at https://doi.org/10.1007/s11356-021$16655-8$. 


13

3

4

5

26

\section{Color removal from wastewater using a synthetic high performance antifouling GO-CPTMS@Pd-TKHPP/polyether sulfone nanofiltration membrane}

Foad Gholami $^{1}$, Sirus Zinadini ${ }^{1 *}$, Soheila Nakhjiri Kamrani ${ }^{2}$, Ali Akbar Zinatizadeh ${ }^{1,3}$, Kiumars Bahrami $^{2,4}$

1- Environmental Research Center (ERC), Department of Applied Chemistry, Faculty of Chemistry, Razi University, Kermanshah, Iran

2- Department of Organic Chemistry, Faculty of Chemistry, Razi University, Kermanshah 67149 - 67346, Iran

3- Department of Environmental Sciences, University of South Africa, Pretoria, South Africa.

4- Nanoscience and Nanotechnology Research Center (NNRC), Razi University, Kermanshah 67149 - 67346, Iran

(4)

15

6

17

\footnotetext{
*Email: sirus.zeinaddini@gmail.com

Tel/Fax: 0098-8334274559
}

2

27


29 Abstract

30 Modified graphene oxide with 5,10,15,20-tetrakis-(4-hexyloxyphenyl) -porphyrin and palladium (II) (signified by

31 GO-CPTMS@Pd-TKHPP) prepared as a novel antifouling polyether sulfone (PES) blended nanofiller membrane.

32 The membrane efficiency has been analyzed such as pure water flux (PWF), hydrophilicity and antifouling features.

33 By increasing of modified graphene oxide percentage from 0 to $0.1 \mathrm{wt} \%$ in polymer matrix the PWF was incremented

34 from 14.35 to $37.33 \mathrm{~kg} / \mathrm{m}^{2}$.h at 4 bar. The membrane flux recovery ratio (FRR) has been investigated by applying

35 powdered milk solution, the FRR results indicated that the $0.1 \mathrm{wt} \%$ modified graphene oxide membrane showed the

36 positive effect on fouling behavior with Rir and FRR value 8.24 and $91.73 \%$ respectively. The nanofiltration

37 membrane performance was assessed applying the Direct Red 16 dye rejection. It was demonstrated that the optimal

38 membranes ( 0.1 wt.\% modified graphene oxide) had notable dye removal (99.58\% rejection). The results are also

39 verified by measuring the scanning electron microscopy (SEM), water contact angle (WCA) and atomic microscopy

40 analysis (AFM).

41

42

43

44 Keywords: Polyether sulfone, nanofiltration membrane, anti-fouling property, modified graphene oxide, dye removal, 45 wastewater treatment.

46

47

48

49

50

51

52

53

54

55

56

57

58

59 


\section{Introduction}

63 The most important environmental issue with colored wastewater is the removal of colors from the sewage (Elimelech \&Phillip 2011). Industrial colored wastewater produced from textiles, paper, plastics, leather, food, and cosmetics, must be treated before wastewater drains into the environment (to recover paint) to prevent health hazards and degradation of the ecosystem is separated and decomposed (Deka et al. 2014, Moradi et al. 2020). Membrane filtration as a very competitive candidate for water treatment technology has been considered for decades due to energy efficiency, cost effectiveness and membrane stability. Because of this necessity, application of the membrane processes among the modern methods for separation is of high interest for scientists (Ang et al. 2015, You et al. 2012). Polymeric membranes are very popular with regard to their excellent formation and their unique physicochemical properties in water refinery (Warsinger et al. 2018). The high flux permeation, acceptable solid elimination and low clogging are integral requirements for high efficiency of membrane filtration. Despite of, the hydrophobic nature of polymers leads to precipitation of foulant materials (pathogens, NOMs, proteins, polysaccharides, micropollutants and color) on the surface of the membrane, which subsequently diminishes flux permeation (Hairom et al. 2014, Manda et al. 2014). The membrane's chemistry and morphology are affected by organic deposits that have destructive effects and are also an important barrier to the further development of membrane applications. Due to extensive research and efforts, one of the accepted solutions for membrane resistance to clogging for water treatment is to change and improve the membrane's hydrophilicity. The very good dispersion of nanofiller material in the entire membrane matrix, that so-called mix matrix membrane (MMM), in recent years, has brought a new concept for membrane fabrication with high flux, high rejection and high fouling resistance (Mukherjee et al. 2019). Organic and inorganic nanoparticles due to having specific functional point such as high hydrophilicity, high specific surface area and good correction, can be used as appropriate filler to make nanocomposite membranes. The excerpted of nanomaterials that used in this field are: Metal-organic framework (MOF) (Emam et al. 2019), polycitrate-Alumoxane (PC-A) (Pirsaheb et al. 2019), $\mathrm{SiO}_{2}$ nanoparticles (Ding et al. 2019, Zangeneh et al. 2019a), ZnO nanoparticle (Modi \&Bellare 2019), zeolite (Mahmodi et al. 2020a, Mahmodi et al. 2020b), graphene oxide (GO) (Januário et al. 2020, Song et al. 2020, Yuan et al. 2020) and Graphitic carbon nitride $\left(\mathrm{g}-\mathrm{C}_{3} \mathrm{~N}_{4}\right)$ ( $\mathrm{Li}$ et al. 2019).

87 Graphene oxide-based membranes (GO), which are made from two dimensions of GO nanostructures and polymer, are considered as promising candidates for water purification and desalination beyond traditional porous polymer membranes (Fathizadeh et al. 2017, Hegab \&Zou 2015). Considering the high adaptable, high mechanical strength, high surface hydrophilic nature and 2-D interrelation structure for the separation of ions as well as displacement of molecules, graphene oxide based membranes have exhibited excellent performance in relation to high flux and Impressive antifouling (Huang et al. 2013, Koltonow \&Huang 2016, Papageorgiou et al. 2015). Because of agglomeration and the electrostatic repulsion between nanosheets graphene oxide in aqueous solutions, the water stability of the unpolished graphene oxide is weak and tends to break down normally. Therefore, researchers have provided a lot of modification to solve this problem (Chen \&Yan 2010, Hua et al. 2015, Wang et al. 2011). 
Today, researchers have shown that the hydrophilicity of graphene oxide with hydrophilic agents helps to solve the problem of decomposition and clogging of GO and GO based membranes, which strongly suggests that this strategy will help to reduce the contamination of pollutant by modified membranes (Cote et al. 2010, Hu et al. 2016, Lee et al. 2004). Liu and his colleagues, incases of reducing the membrane fouling and degradation of nanosheets by combining triethanolamine (TEOA) with modified titanate nanowires (TNWs) and graphene oxide, they have been made photocatalytic membranes that were able to solve membranes and graphene oxide problems. The results (flux: 42 $\mathrm{L} / \mathrm{m}^{2}$.h and dye rejection: $95 \%$ ) show that the modified membrane, due to its efficient modifications, has a high degree of anti-fouling and hydrophilicity that was used to remove Congon Red dye (Liu et al. 2017b). Huang et al., In 2014, developed a combination of graphene oxide and metal-organic framework (ZIF-8) to improve the membrane's performance for better separation of gases, which in bicontinuous ZIF-8@GO based membrane increased hydrogen permselectivity relative to the unmodified state due to the presence of graphene oxide (Huang et al. 2014). In the next work that introduced in 2017, Ayyaru and Ahn donated hydrophilicity and antifouling properties to the PVDF nanocomposite ultrafiltration membranes by inserting sulfonated graphene oxide (SGO). According to the results, due to the improvement of the graphene oxide by the $-\mathrm{SO}_{3} \mathrm{H}$ agent, the water permeation flux increased $146.6 \%$ and flux recovery ratio (88.7\%) compared to the unmodified graphene oxide (water flux: 53.3\% and FRR: $75 \%$ ), this indicating that the problem of graphene oxide and the membrane have also been resolved (Ayyaru \&Ahn 2017). In 2018, Abdi and coworker presented a hybrid combination (metformin/GO/Fe $3 \mathrm{O}_{4}$ ) that was successfully introduced into the polymeric membrane for removal of colored materials and heavy metals. The results of this combination were high hydrophilicity, PWF and antifouling effect, which has been applied to remove direct red-16 and copper ions with $99 \%$ and 92\% removal, respectively (Abdi et al. 2018). The graphene oxide framework that built by use of 1,4cyclohyxanediamine (CDA) and p-phenylenediamine (pPDA), was introduced by Qian and et al. in 2018 and exposed in the field of modified graphene oxide. The synthesized composition was used in the alumina membrane, which showed great results, that can be mention to high flux $\left(20.1 \mathrm{~kg} / \mathrm{m}^{2} . \mathrm{h}\right)$ and high ionic rejection (99.9\%) (Qian et al. 2018).

In this work, for the first time, the modified GO nanoparticle (is shown as GO - CPTMS@Pd - TKHPP) was used in the PES nanofiltration matrix. In order to evaluate the effect of modified graphene oxide nanosheets on membrane performance removing the dye, surface hydrophilicity, antifouling capability, and permeability were examined. Membranes structure was evaluated with SEM, water contact angle and AFM analysis. The antifouling capability of modified membranes was assessed during direct red-16 and methylene blue filtration.

\section{2. Materials and methods}

\section{2.1. Materials}

127 The Polyvinyl pyrrolidone (PVP) ( $\mathrm{M}_{\mathrm{w}}=25,000 \mathrm{~g} / \mathrm{mol}$ ) was obtained (Merck Co., Germany). dimethylacetamide (DMAc) and PES ( $\mathrm{M}_{\mathrm{w}}=58000 \mathrm{~g} / \mathrm{mol}$ ) were pouched (BASF Co., Germany). in all experiment distilled water has been powder, 3-(choloropropyl)-trimethoxysilane palladium (II) chloride, dimethylformamide (DMF) and ethanol was 
prepared from Merck, Germany. All the chemical reagents used in our experimental were used without further purification.

\subsection{Modified graphene oxide nanocomposites preparation}

The GO-CPTMS@Pd-TKHPP (Fig. 1) was synthesized by the following methods:

According to the usual way, graphene oxide (GO) was prepared based on modified hummers method from graphite powder (Zaaba et al. 2017), then graphene oxide-3-(choloropropyl)-trimethoxysilane (GO-CPTMS) was synthesized by adding CPTMS to GO in a solution of toluene then the mixture was stirred and refluxed for $24 \mathrm{~h}$ at $110{ }^{\circ} \mathrm{C}$, the solid was filtered and dried, after this 4. 5,10,15,20-tetrakis-(4-hydroxyphenyl)-porphyrin (THPP) was prepared, synthesis of THPP was achieved according to the following procedure. Pyrrole was leisurely added under stirring to a solution of 4-Hydroxy benzaldehyde in refluxing propionic acid. Refluxing was continued for 2 hours, after this step the reaction mixture was washed several time and cooled slowly, filtered and dried, the dark purple crystalline product was precipitated. Then THPP was added to a solution of GO-CPTMS in refluxing dioxane and in the presented of $\mathrm{Na}_{2} \mathrm{CO}_{3}$ and KI, black powder of GO-CPTMS@THPP was obtained. Next 3-(choloropropyl)-trimethoxysilan 5,10,15,20-tetrakis-(4-(hexyloxy) phenyl)-porphyrin GO-CPTMS@Pd-TKHPP was obtained by adding 1bromohexane to a solution of DMF and $\mathrm{K}_{2} \mathrm{CO}_{3}(4: 4)$ in a flask and GO-CPTMS@THPP, then the obtained mixture was refluxed up for $24 \mathrm{~h}$, then dried and the gray powder was obtained. Finally, GO-CPTMS@Pd-TKHPP was obtained by adding $\mathrm{PdCl}_{2}$ to GO-CPTMS@Pd-TKHPP in the presence of ethanol solvent and reflux condition for near 24 h (Bahrami \&Kamrani 2018).

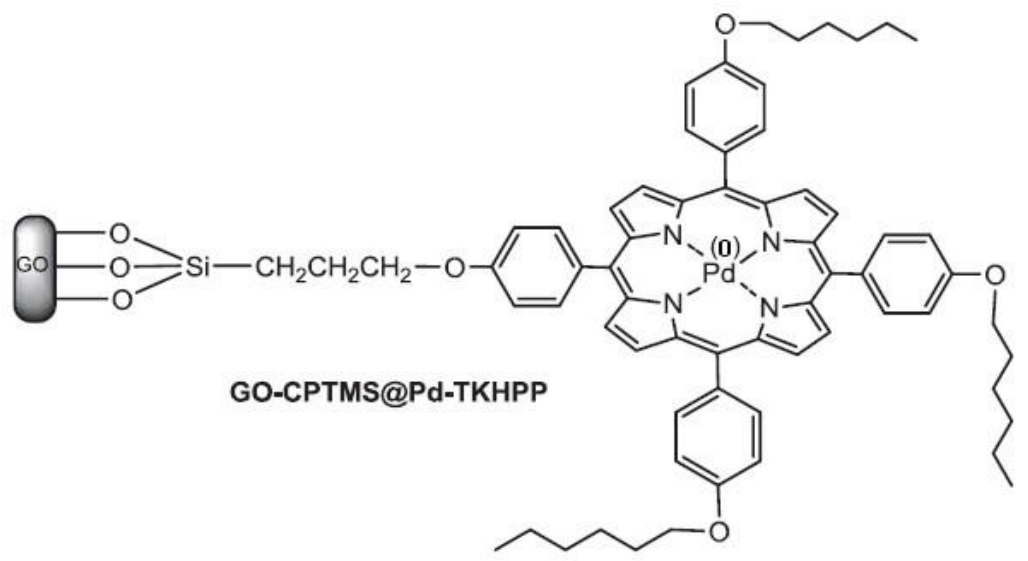

Fig. 1. scheme of GO-CPTMS@Pd-TKHPP.

\subsection{Preparation of modified mixed matrix PES-GO membrane:}

The unmodified and modified membranes were carried out via phase inversion method. The membrane solution composition for all cases has been listed in Table 1. In order to form the homogenous solution, first a proper amount of modified GO was added into DMAc and sonicated (DT 102H Bandelin ultrasonic (Germany)) for 30 minutes. Then, PVP and PES were added to obtained solution. After this step, the casting solution was kept on continues stirrer overnight at room temperature. Finally, in order to increase the amount of homogeneity, dope solutions were sonicated again (20 min) to make sure all air bubbles have been removed and impressive dispersing is done. Finally, by using a 
self-made knife, the solutions were casted on glassy plates (150 $\mu \mathrm{m}$ thickness) and immediately (without evaporation) moved to distilled water (nonsolvent bath at RT). After forming the polymeric membrane, they were moved to fresh distilled water (24h). This will be removed water soluble components from membrane matrix. Finally, the obtained membranes were warped between paper for drying (24h) (Zinadini et al. 2014).

Table 1. Casting solution compositions.

\begin{tabular}{ccccc}
\hline Membrane type & PES (wt.\%) & PVP (wt.\%) & Modified graphene oxide (wt.\%) & DMAc (wt.\%) \\
\hline $\mathrm{M}_{1}$ & 20.0 & 1.0 & 0.0 & 79.0 \\
$\mathrm{M}_{2}$ & 20.0 & 1.0 & 0.1 & 78.9 \\
$\mathrm{M}_{3}$ & 20.0 & 1.0 & 0.5 & 78.5 \\
$\mathrm{M}_{4}$ & 20.0 & 1.0 & 1.0 & 78.0 \\
\hline
\end{tabular}

\subsection{Characterization of modified GO membranes:}

The membrane morphology was considered applying scanning electron microscope (SEM) (Philips-XL30, The Netherland) (20 kV acceleration voltage) first, membranes were cut and cleaned with filter paper to clean probable contaminant. Then they were immersed into liquid Nitrogen for 50-70 seconds. After that for membrane drying the frozen membranes were breaking and kept at RT (room temperature). Afterward, the dried membranes were coated by $\mathrm{Au}$ ion in order to produce electron conductivity. As the final step SEM images were captured (20kV in high vacuum condition).

The surface roughness for prepared membrane was analyzed applying atomic force microscopy (AFM) (Nanosurf® Mobile S (Switzerland)) this device was equipped by an optical probe microscope. Small square samples were prepared $(2 * 2 \mathrm{~cm})$ and fixed on a holder and the surface was scanned $(4.4 \mu \mathrm{m} * 4.4 \mu \mathrm{m})$. The results reflected as (Sa) mean roughness, the root of square data (Sq) and average difference between highest peak and the lowest valley (Sz) have been achieved with quantitative analyze.

172 A recent method to analyze the hydrophilicity of membranes, is water contact angle (WCA) (G10, KRUSS, Germany)

173 measurement. The propensity of small distilled water droplets to extend on the membrane surface is known as 174 membrane hydrophilicity. For WCA measurement, in all cases, $2 \mu 1$ of deionized water have been used. For reducing 175 experimental errors, all examinations were repeated in 4 random sites and the mean valve was reported.

\section{2.5. Membrane performance}

\section{2.5.1. Pure water flux and antifouling experiments}

178 Membrane performance, pure water flux (PWF) and antifouling attributes of modified NF membranes with GO were 179 examined in a dead-end setup (Fig. 2 a) $\left(150 \mathrm{ml}\right.$ and $\left.12.56 \mathrm{~cm}^{2}\right)$. As trance membrane pressure (TMP) Nitrogen

180 cylinder the cell was equipped to force the feed pass through the membrane. In order to concentration polarization 181 reduction, constant simulation was applied for the cell (400 rpm). In order to earn stably state, for the first 30 min of experiment the TMP was compressed at 5 bar then it was reduced to 4 bar (Gholami et al. 2017). Based on equation 1833 the PWF was calculated:

$$
J_{W .1}=\frac{M}{A \Delta \mathrm{t}}
$$


Which, $\Delta \mathrm{T}$ is the time of permeation, $\mathrm{A}\left(\mathrm{m}^{2}\right)$ is touching surface and $\mathrm{M}$ is the weight of permeation.

Milk powder solution (8000 ppm), to consider the antifouling properties were tested as proper foulant (after PWF test). The milk powder permeation $\left(J_{P}\left(\mathrm{~kg} / \mathrm{m}^{2} . \mathrm{h}\right)\right)$ was tested based on water permeation during the analyzed (4 bar, $90 \mathrm{~min}$ ). After that test, fouled membrane was cleaned with deionized water (15 min immersed in water without any backwash) then the pure water flux as tested a gained with distilled water. Based on following equation, the FRR can be calculated as:

$$
F R R=\left(\frac{J_{W 2}}{J_{W 1}}\right) \times 100
$$

As a matter of fact, higher $F R R$ for membranes indicates distinct antifouling ability of the nanofiltration membranes. Following the results in order to consider antifouling behavior, during filtration resistance fouling ratio was evaluated in detail, irreversible fouling (Rir), reversible fouling (Rr) and total fouling (Rt) were investigated according to equations:

$$
\begin{aligned}
& R_{t}(\%)=\left(1-\frac{j_{p}}{j_{W 1}}\right) \times 100=R_{i r}-R_{r} \\
& R_{r}(\%)=\left(\frac{j_{W 2}-j_{p}}{j_{W 1}}\right) \times 100 \\
& R_{i r}(\%)=\left(\frac{j_{W 1}-j_{W 2}}{j_{W 1}}\right) \times 100
\end{aligned}
$$
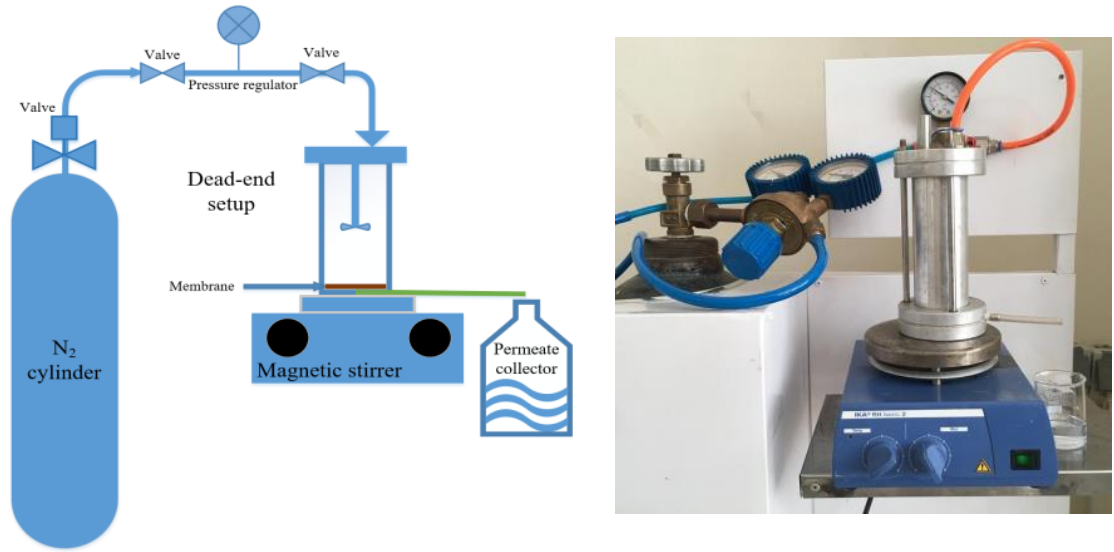

(a)
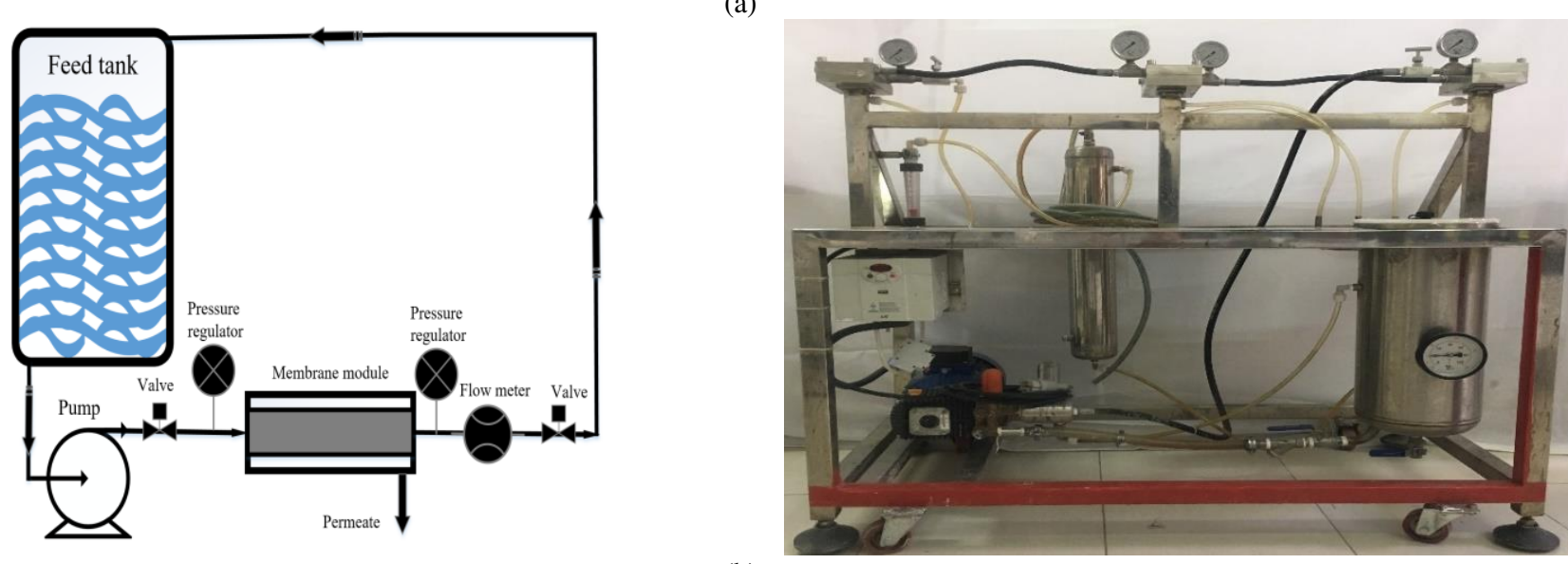

(b)

Fig. 2. Schematic of the (a) dead-end setup and (b) cross-flow setup. 


\subsection{Dye removal}

201 As dye containing azo groups direct red-16 was chosen. In this case, to consider membrane efficiency, the filtration was operated in dead-end setup (120 min at 4 bar), each run was tested by $150 \mathrm{ml}$ of feed. After this step in order to evaluate long term filtration and industrial simulation, cross-flow setup (Fig. 2 b) was applied (driving force 4 bar, flow rate $300 \mathrm{~L} / \mathrm{h}$ at $420 \mathrm{~min}$ ). In all experiments to propose of feed simulation, $50 \mathrm{mg} / \mathrm{L}$ of direct red-16 was chosen, which is in the range of typical textile wastewater industries. As a result, the flux recovery ratio and flux were reported based on equations 4 and 3. By using UV-Vis spectrophotometer $(520 \mathrm{~nm}$ for direct red-16 and $665 \mathrm{~nm}$ for methylene blue) (JENWAY 6320D) according to equation 8 the rejection was calculated:

$$
(\%)=\left(1-\frac{C_{p}}{C_{f}}\right) \times 100
$$

where, $\mathrm{C}_{\mathrm{f}}$ is feed concentration and $\mathrm{C}_{\mathrm{p}}$ is permeated concentration of dye $(\mathrm{mg} / \mathrm{L})$.

\section{3. Results and discussion}

\section{3.1. modified graphene oxide nanocomposites Characterization}

212 The prosperous synthesis of the GO-CPTMS is confirmed by the FT-IR spectra (Fig. 3. c). The peak turning up at 810

$213 \mathrm{~cm}^{-1}$ comes back to $\mathrm{Si}-\mathrm{O}-\mathrm{Si}$ the symmetric vibration. The peak at $1107 \mathrm{~cm}^{-1}$ relevant to asymmetrical $\mathrm{Si}-\mathrm{O}-\mathrm{Si}$ 214 stretching. About GO-CPTMS@TKHPP (Fig. 3. e), recognized that peak of the N-H bending and stretching 215 frequencies located at $\sim 3,300 \mathrm{~cm}^{-1}$ and $~ 960 \mathrm{~cm}^{-1}$ and shown free base porphyrins. When the $\mathrm{PdCl}_{2}$ was interred into 216 the porphyrin ring, the N-H peak vibration of free base porphyrins vanished and features of the functional groups of 217 Pd-N bond shaped at $\sim 1,009 \mathrm{~cm}^{-1}$ (Fig. 3. f), that analyzed the configuration of a metal-ligand bond (Bahrami 218 \&Kamrani 2018).

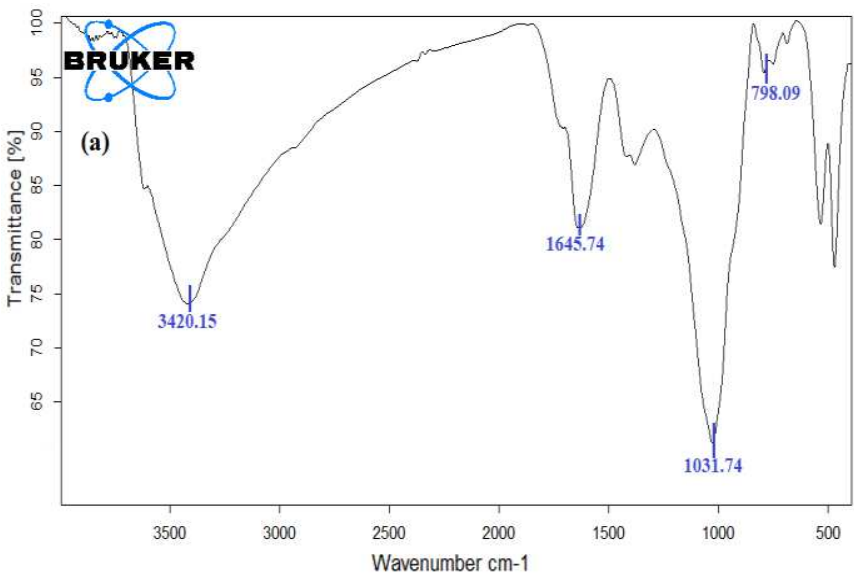

(a)

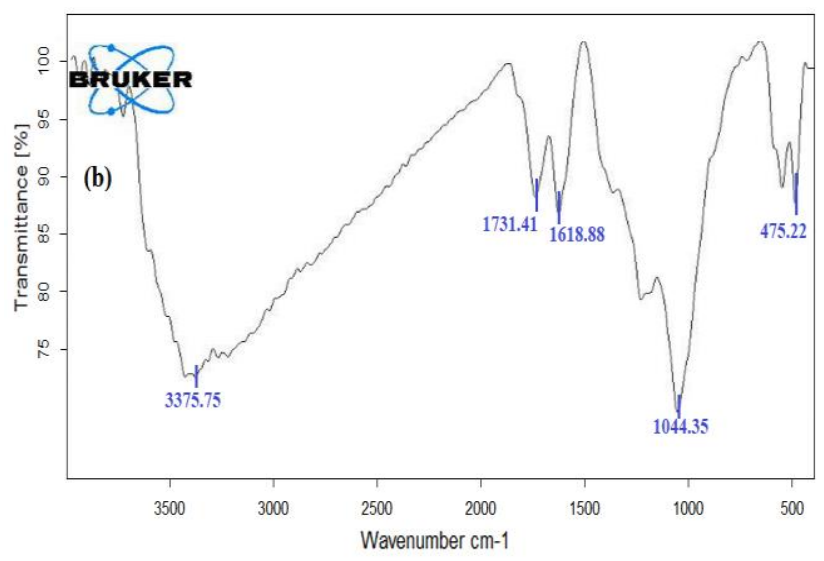

(b) 


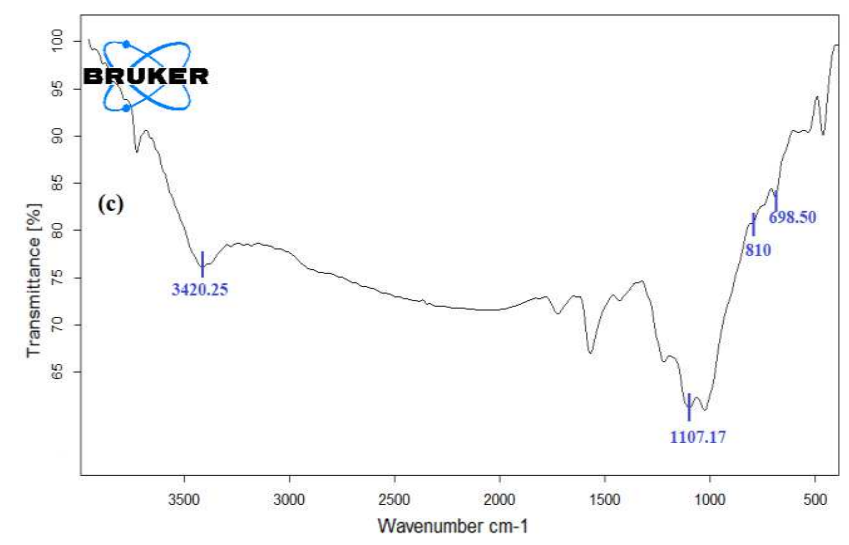

(c)

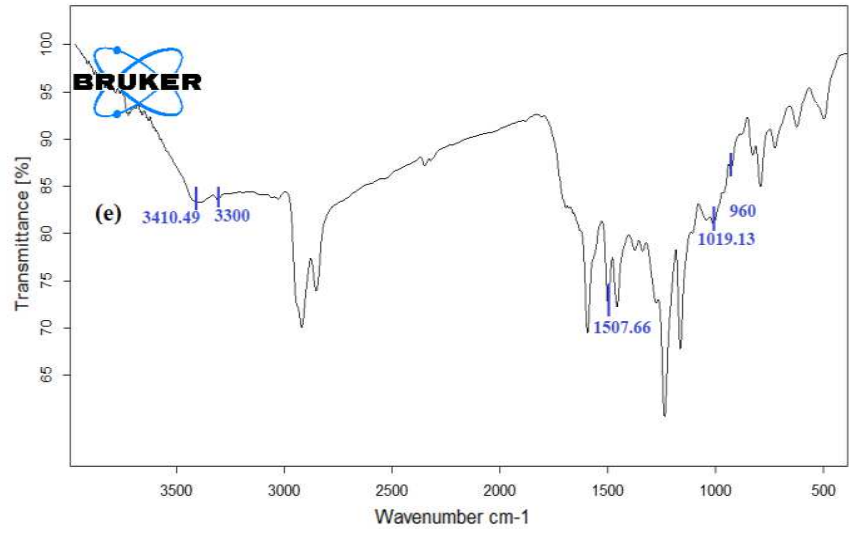

(e)

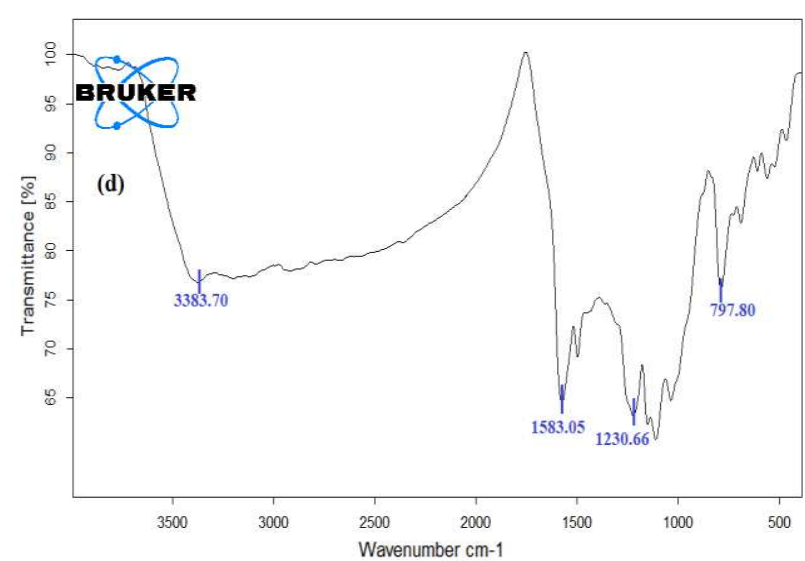

(d)

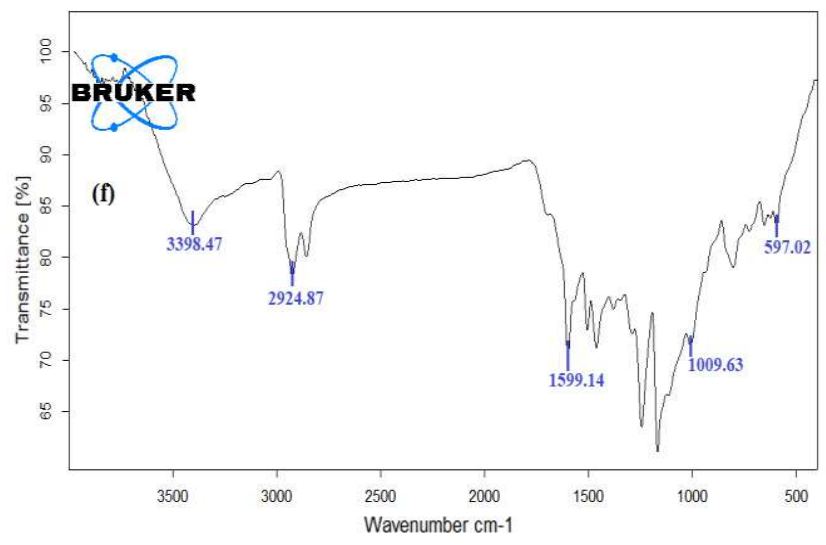

(f)

Fig. 3. FT-IR spectrum of (a) FT-IR spectra of GO, (b) GO-OH, (c) GO-CPTMS, (d) GO-CPTMS@THPP, (e) GO- CPTMS@TKHPP and (f) Recycled GO-CPTMS@Pd-TKHPP.

219 In Fig. 4, the EDX analysis of nanosheets (GO-CPTMS@Pd-TKHPP) displayed the attendance of the anticipation 220 elements in the nanosheets of GO such as silicon, oxygen, palladium, nitrogen, and carbon. As can been seen, the 221 element distribution of the Si-Pd/GO is approximately 1.43 (Zhang et al. 2017).

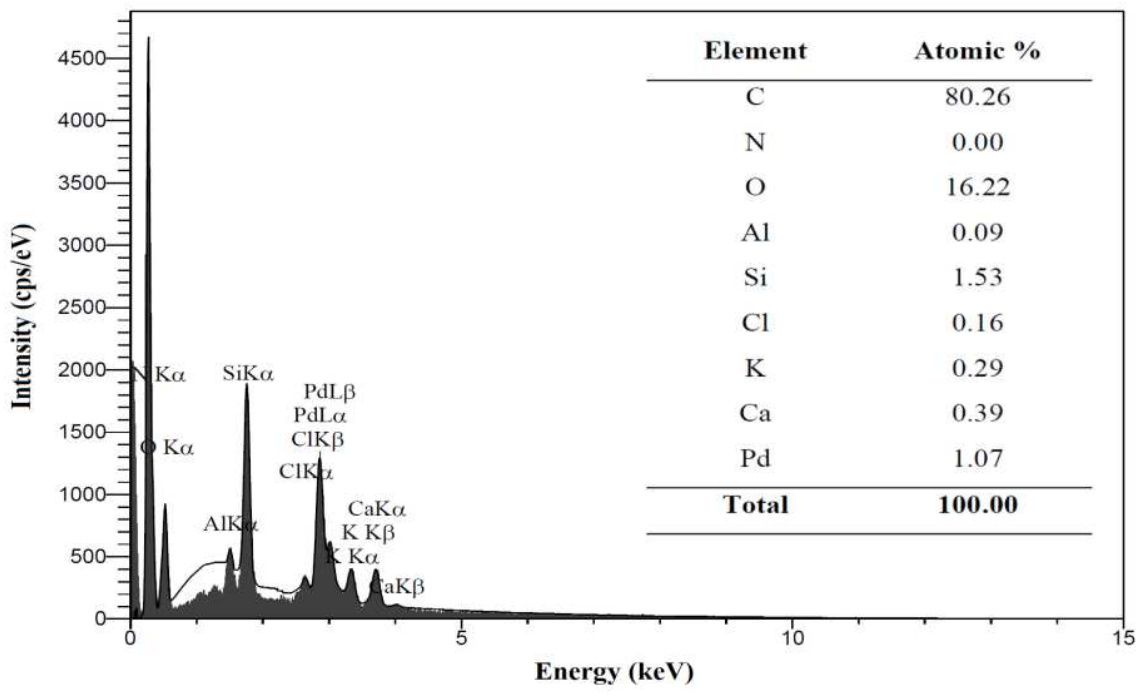

Fig. 4. GO-CPTMS@Pd-TKHPP EDX pattern. 

correspond to (111), (200), (220) and (331) crystalline planes of Pd, respectively, illustrated that Pd element does not

224 exist in the form of Pd(II) and it was shown Pd (0) (Fig. 5) (Fareghi-Alamdari et al. 2016, Zolfigol et al. 2013).

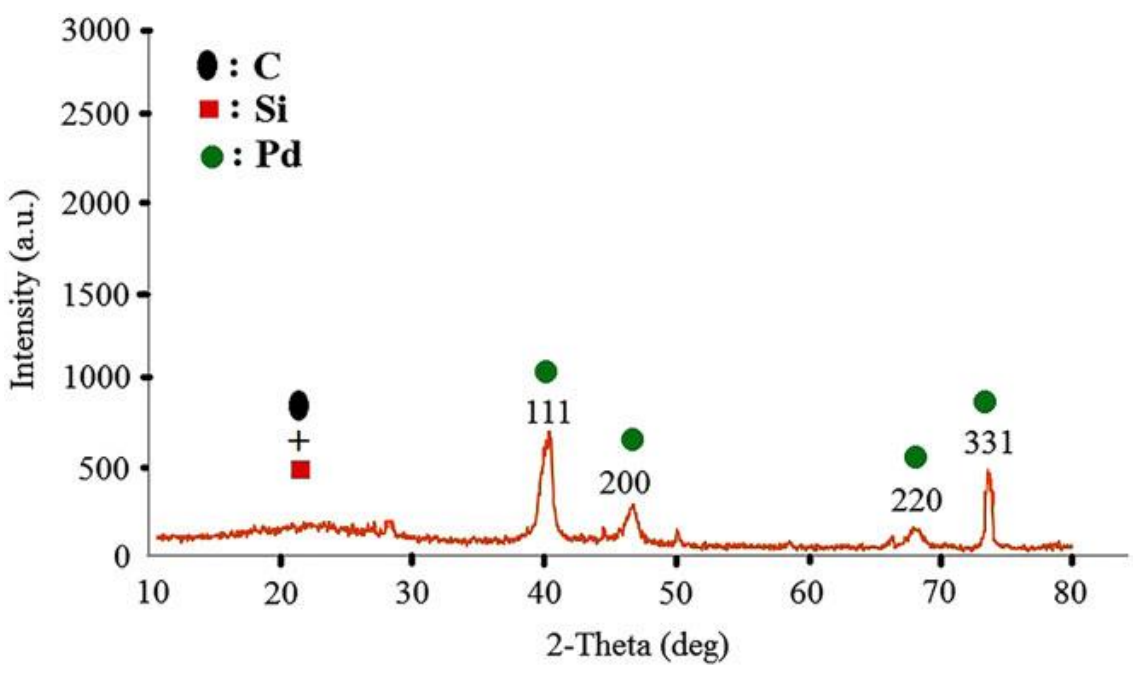

Fig. 5. GO-CPTMS@Pd-TKHPP XRD pattern.

The stratification structure of GO-CPTMS@Pd-TKHPP was also perceived from transmission electron microscopy (TEM) and scanning electron microscopy (SEM). The scanning electron microscopy (SEM) illustration of GOCPTMS@Pd-TKHPP (Fig.6. a) shows the ingredient scale, morphology and superficies sameness. transmission electron microscopy (TEM) image of the GO-CPTMS@Pd-TKHPP indicated which Pd(II)-TKHPP was seated on the surface of graphene oxide (Fig. 6. b) (Bahrami \&Kamrani 2018).

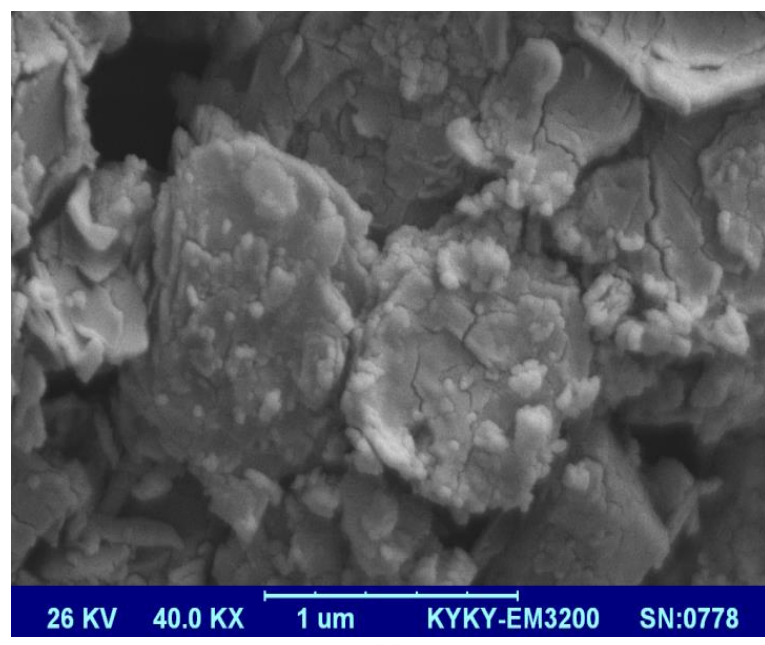

(a)

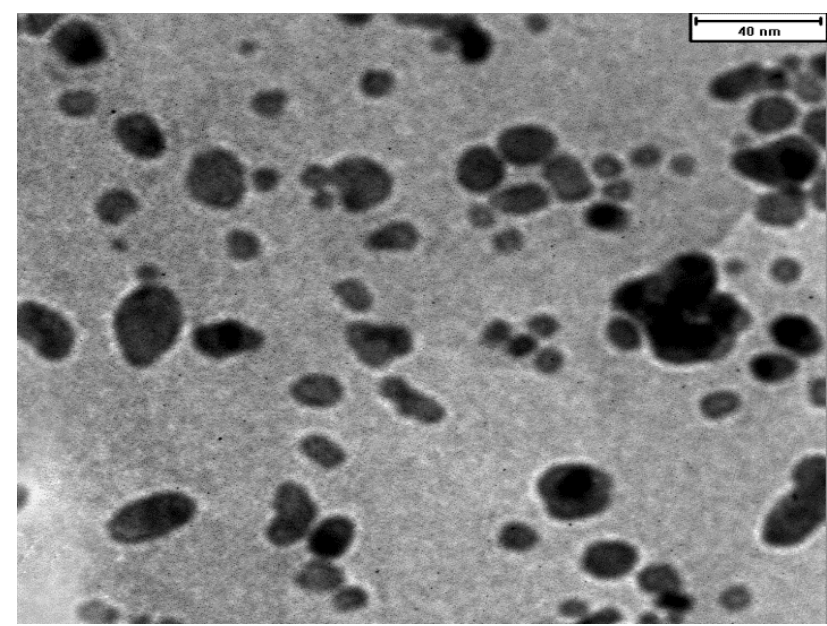

(b)

Fig. 6. a) GO-CPTMS@Pd-TKHPP SEM images, b) GO-CPTMS@Pd-TKHPP TEM images.

\subsection{Morphology analysis}

231 In order to consider, the effect of GO-CPTMS@Pd-TKHPP concentration on the structure and morphology of the

232 membrane, SEM images are shown in Fig. 7. As shown in picture, asymmetric structure with a uniform dispersion of 
nanoparticles is visible and can be easily recognized as finger-like pores with thin top layer and thick bottom layer

234 due to fast immigration of hydrophilic NPs in phase inversion step. The identical building of the membranes, implies

235 that the impact of nanoparticles on morphology was low. So, this result shows that was not an important influence on

236 the formation of mold membrane. Small differences in the structure of membranes at low concentrations were

237 observed that described the increase in porosity and consequently increase the radius of pores. In different

238 concentrations of nanoparticles, $0.1 \mathrm{wt}$ \% provided minimum thickness of the top layer in the membrane. As seen in

239 Fig .8, by adding 0.1 wt.\% modified graphene oxide nanocompound, the porosity was increased and further increase

240 in the amounts of the nanosheets to more than 0.1 wt.\% caused the reduction of pore radius (Vatanpour et al. 2011).
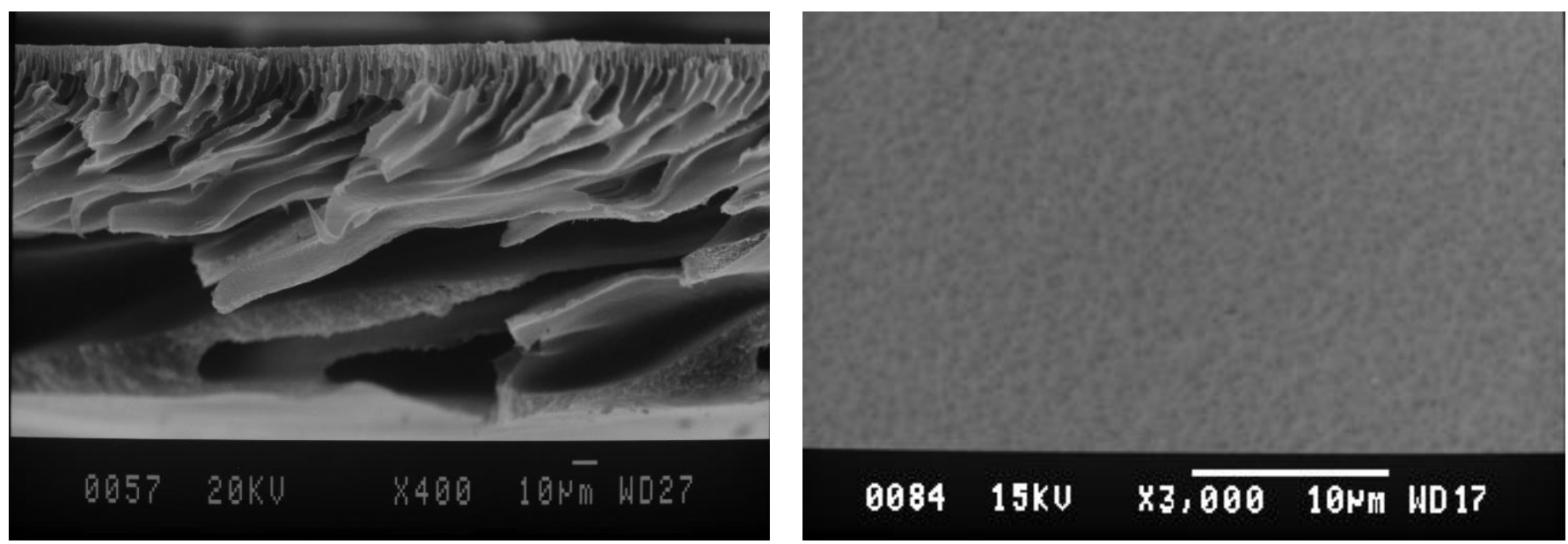

$\mathrm{M}_{1}$
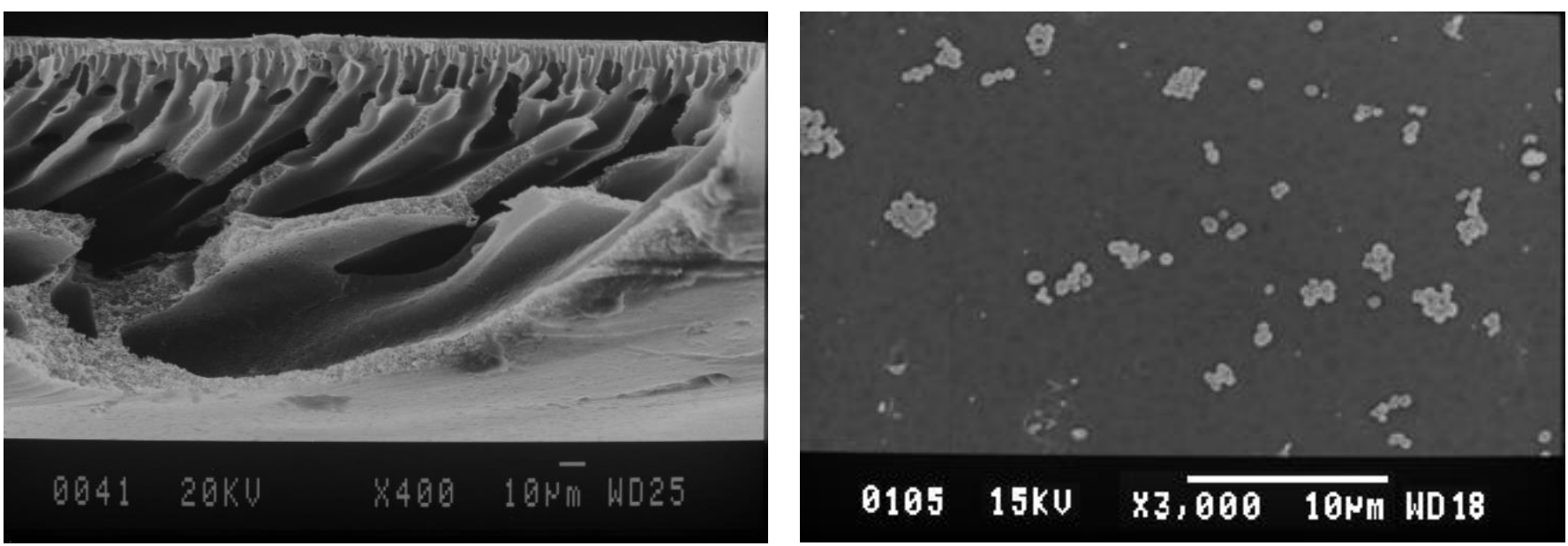

$\mathrm{M}_{2}$ 

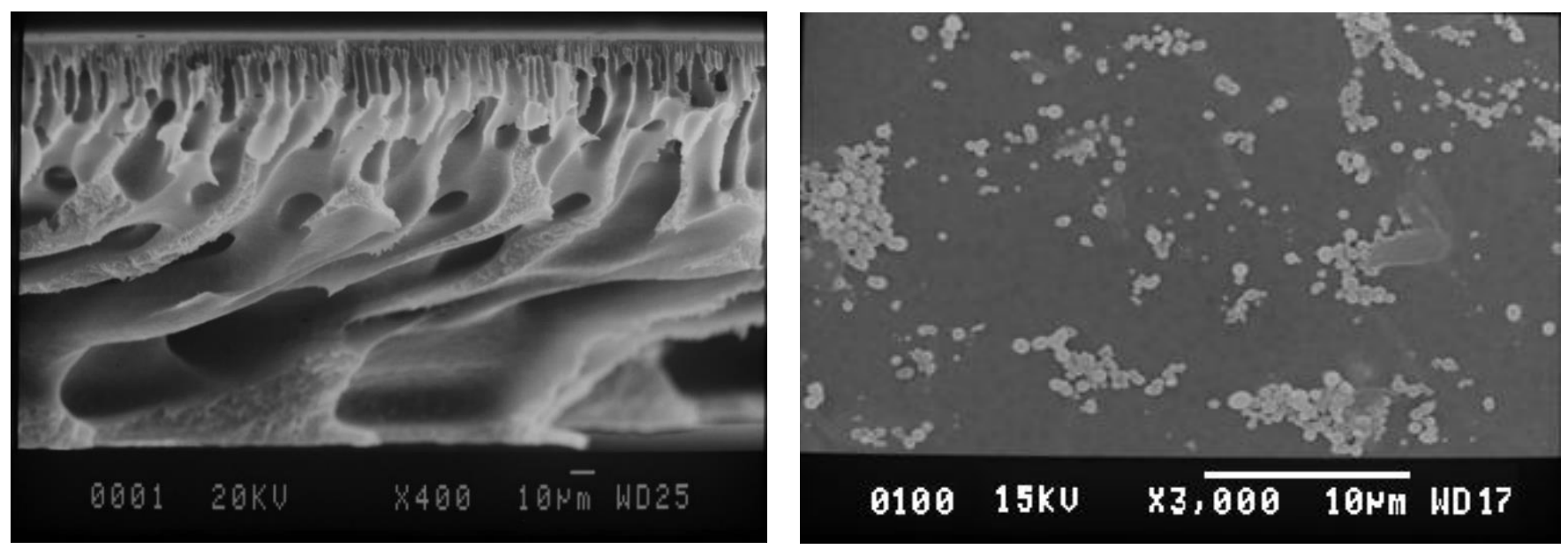

$\mathrm{M}_{3}$
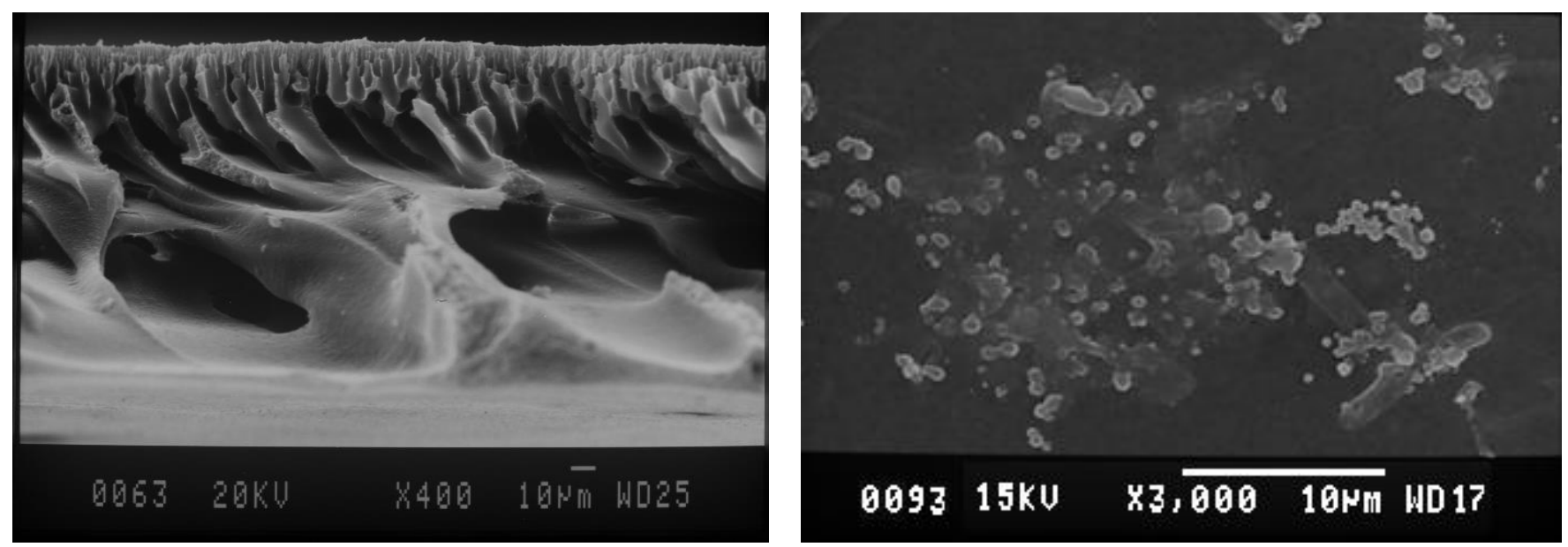

$\mathrm{M}_{4}$

Fig. 7. SEM images cross-section and surface (M1 =unfilled. $\%, \mathrm{M} 2=0.1 \mathrm{wt} . \%, \mathrm{M} 3=0.5 \mathrm{wt} . \%$ and $\mathrm{M} 4=1.0 \mathrm{wt} . \%$ ).

\section{$241 \quad 3.3$ The prepared membranes pure water flux and hydrophilicity}

242 Water contact angle measurement can be used to identify the hydrophilicity surface of prepared membranes. As

243 illustrated in Table 2, by adding nanofiller to the membrane matrix, a logical trend on WCA reduction can be observed.

244 It should be noted that, due to presenting hydrophilic functional group on the GO, the membrane hydrophilicity was

245 increased (membrane contact angle was decreased), causing an increase in membrane permeability due to hydrogen

246 bonding between water and membrane surface.

Table 2. Water contact angle of the produced nanofiltration MMM

\begin{tabular}{lcccc}
\hline & $\mathrm{M}_{1}$ & $\mathrm{M}_{2}$ & $\mathrm{M}_{3}$ & $\mathrm{M}_{4}$ \\
\cline { 2 - 5 } Water contact angle, $^{\circ}$ & $75.22 \pm 1.50$ & $59.20 \pm 1.18$ & $54.70 \pm 1.09$ & $50.20 \pm 1.00$ \\
\hline
\end{tabular}

247 Flux transmission depends on many factors that hydrophilicity is one of the most important cases. The hydrophilic

248 functional groups of the GO-CPTMS@Pd-TKHPP on the membrane surface caused a change in the pure water flux 249 (PWF) that established hydrogen bonds between water molecules and membrane surface (Fig. 8). Adding the 
nanoparticles up to $0.1 \mathrm{wt} \%$, led to an increase in $\operatorname{PWF}\left(\mathrm{M}_{2}\right)$. By adding nanoparticles to membrane matrix increment is notable for $\mathrm{M}_{2}$. In higher loadings $\left(\mathrm{M}_{3}, \mathrm{M}_{4}\right)$ accumulation effect caused PWF reduction might be due to porosity occupation (Fig. 8). It should be noted that the powdered milk solution rejection was more than 98\%. Showing

253 interrelation between flux increment and defects or cracks in the membrane due to poor bond between the modified 254 graphene oxide and PES.

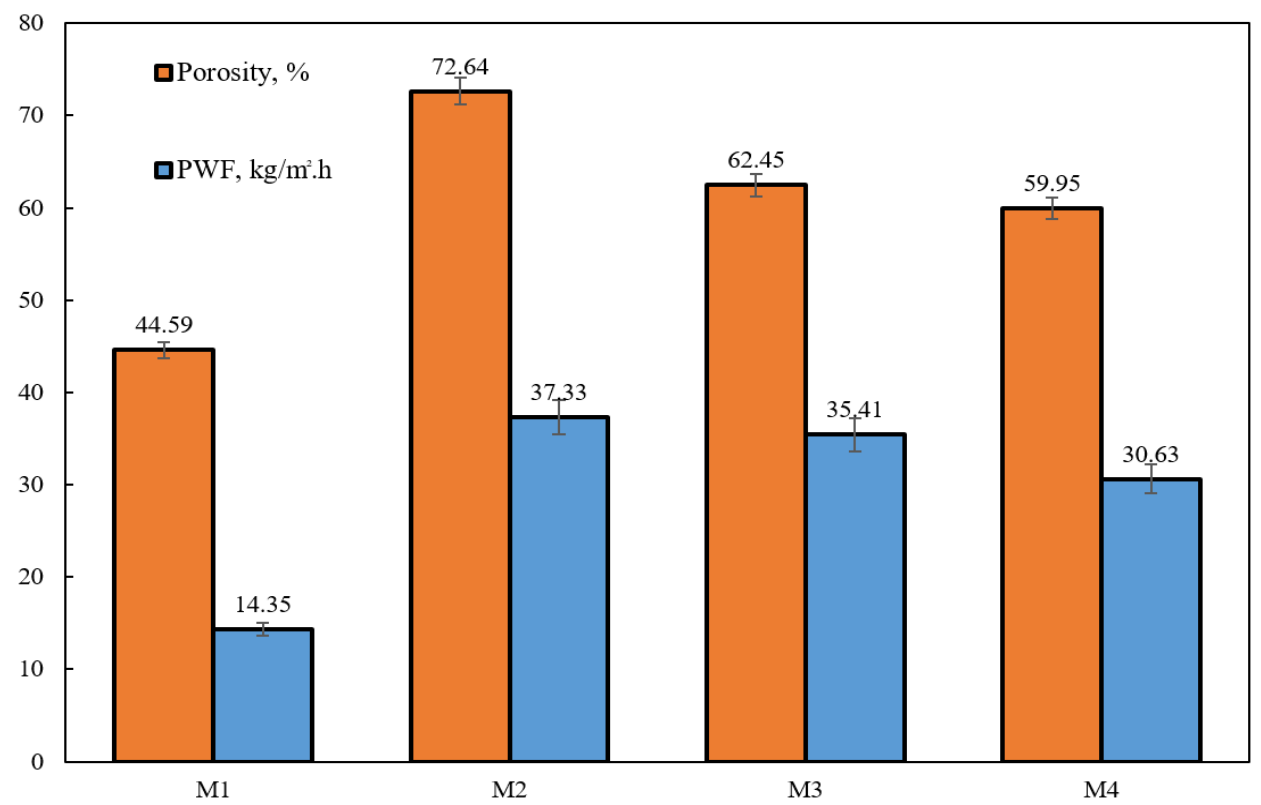

Fig. 8. $P W F$ and porosity of the modified graphene oxide blended PES nanofiltration membranes $\left(M_{1}=u n f i l l e d, M_{2}=0.1\right.$ wt. $\%, \mathrm{M}_{3}=0.5$ wt. $\%$ and $\mathrm{M}_{4}=1.0$ wt. $\left.\%\right)$.

\section{$255 \quad 3.4$ Fouling behavior of the prepared membranes}

256 Fig. 9 shows the antifouling performance of prepared membrane in three step filtration. The results of 0.1 wt.\% of modified graphene oxide $\left(\mathrm{M}_{2}\right)$ demonstrated the highest permeability compared to the other concentrations. As can be obtained (Fig. 9), the difference in flux, in the first step and third step, observed between the modified and unmodified membranes is caused by the presence of hydrophilic function group on the GO surface, which has been donated to have a hydrophilic effect on the PES membrane. 


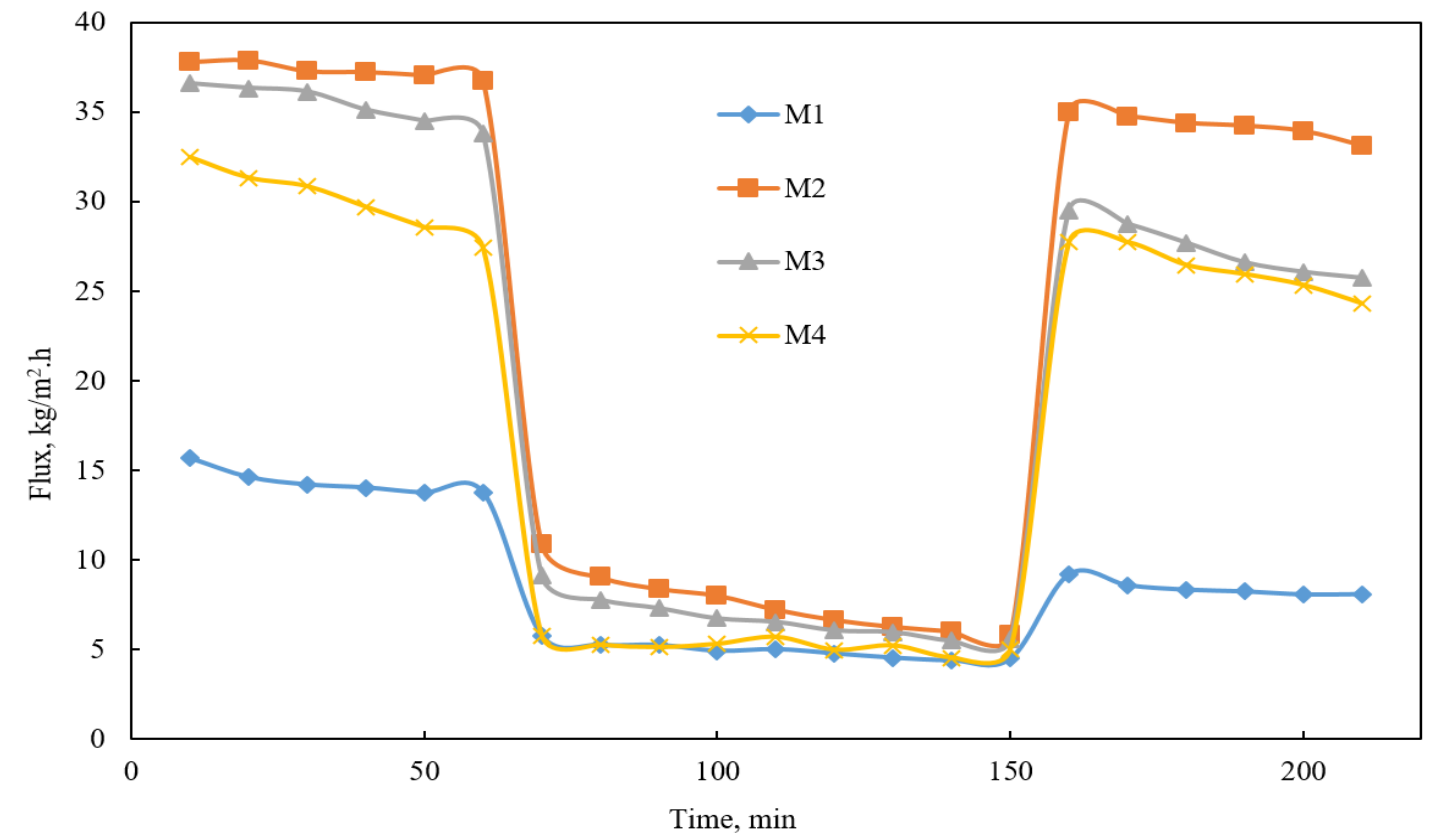

Fig. 9. Flux against time of the membranes with different concentrations of modified graphene oxide nanosheets. The filtration process includes three phases: water flux, milk powder filtration and second water flux after washing fouled membranes $\left(\mathrm{M}_{1}=\mathrm{unfilled}\right.$, $\mathrm{M}_{2}=0.1$ wt. $\%, \mathrm{M}_{3}=0.5$ wt. $\%$ and $\left.\mathrm{M}_{4}=1.0 \mathrm{wt} . \%\right)$.

261 FRR is one of the important parameters for antifouling assessment. The FRR diagram was displayed in Table 3. The 262 greatest FRR for membrane has been achieved for membrane embedded with 0.1 wt.\% $\left(\mathrm{M}_{1}\right)$ of modified graphene oxide. Antifouling performance of embedded mixed matrix membranes could be related to hydrophilicity for modified membranes although this effect has an optimal ratio $\left(\mathrm{M}_{2}\right)$ in higher additives due to agglomeration effect on the acceptable trend (FRR reduction) is notable. That was induced by remaining functional groups of GO-CPTMS@PdTKHPP on the membrane surface. Creating a hydration layer on the membrane surface due to the presence of hydrophilic nanosheets and hydrogen bonding can inhibit the formation of foulant layer on the membrane surface. The results demonstrated that the addition of the modified graphene oxide nanosheets (ingenious design with effective groups) in the PES membrane was useful to improve membrane permeability (Ng et al. 2013).

Table 3. FRR of the prepared nanocomposite membranes infiltration of powdered milk solution.

\begin{tabular}{lccccc}
\hline & $\mathrm{M}_{1}$ & $\mathrm{M}_{2}$ & $\mathrm{M}_{3}$ & $\mathrm{M}_{4}$ & \\
\cline { 2 - 5 } Flux recovery ratio, $\%$ & 58.65 & 91.73 & 78.3 & 88.99 \\
\hline
\end{tabular}




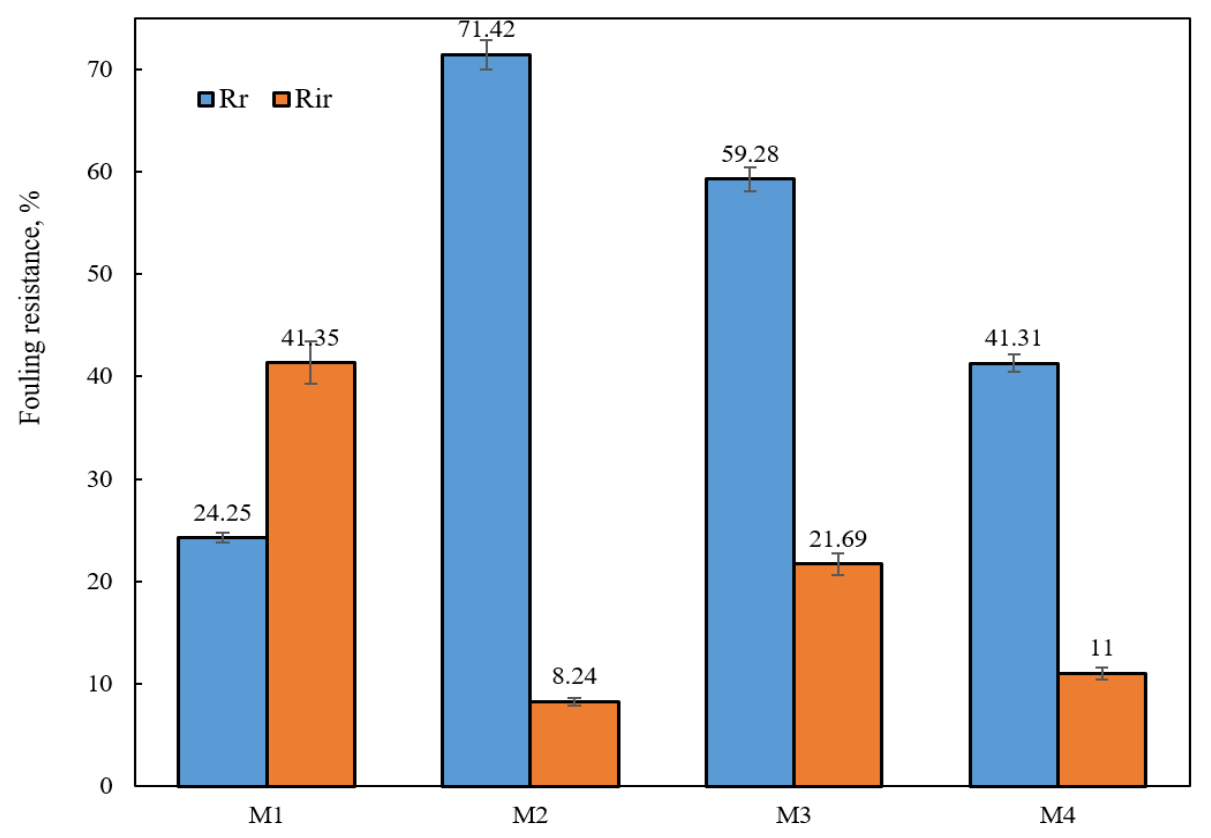

Fig. 10. Fouling resistance ratio of modified graphene oxide-PES ultrafiltration membranes $\left(\mathrm{M}_{1}=u n f i l l e d, \mathrm{M}_{2}=0.1 \mathrm{wt} . \%\right.$,

$$
\left.\mathrm{M}_{3}=0.5 \text { wt. } \% \text { and } \mathrm{M}_{4}=1.0 \mathrm{wt} . \%\right) \text {. }
$$

276 AFM technique was used for measuring the membranes surface roughness. As a matter of fact lower roughness replies 277 on stronger antifouling property. In addition, foulants may be trapped in the valleys of membrane with unusual surfaces 278 resulting in clogging of the valleys. The AFM and its associated results are presented in Fig. 11 and Table 4. The 279 average roughness $(\mathrm{Sa})$ of the bare nanofiltration membrane changed from 21.251 to $8.003 \mathrm{~nm}$ for the modified 280 membranes with 0.1 wt.\% of GO-CPTMS@Pd-TKHPP, and then enhanced to $9.707 \mathrm{~nm}$ for the modified graphene 281 oxide $1 \mathrm{wt} \%$. In the lower concentration of modified graphene oxide, because of less electrostatic interactions between 282 the modified graphene oxide, they are tidied in membrane symmetrically, resulting in a smooth membrane surface. 283 But, due to increment in agglomeration and pore size of modified graphene oxide, membrane surface roughness was enhanced at higher concentration of modified graphene oxide [9].
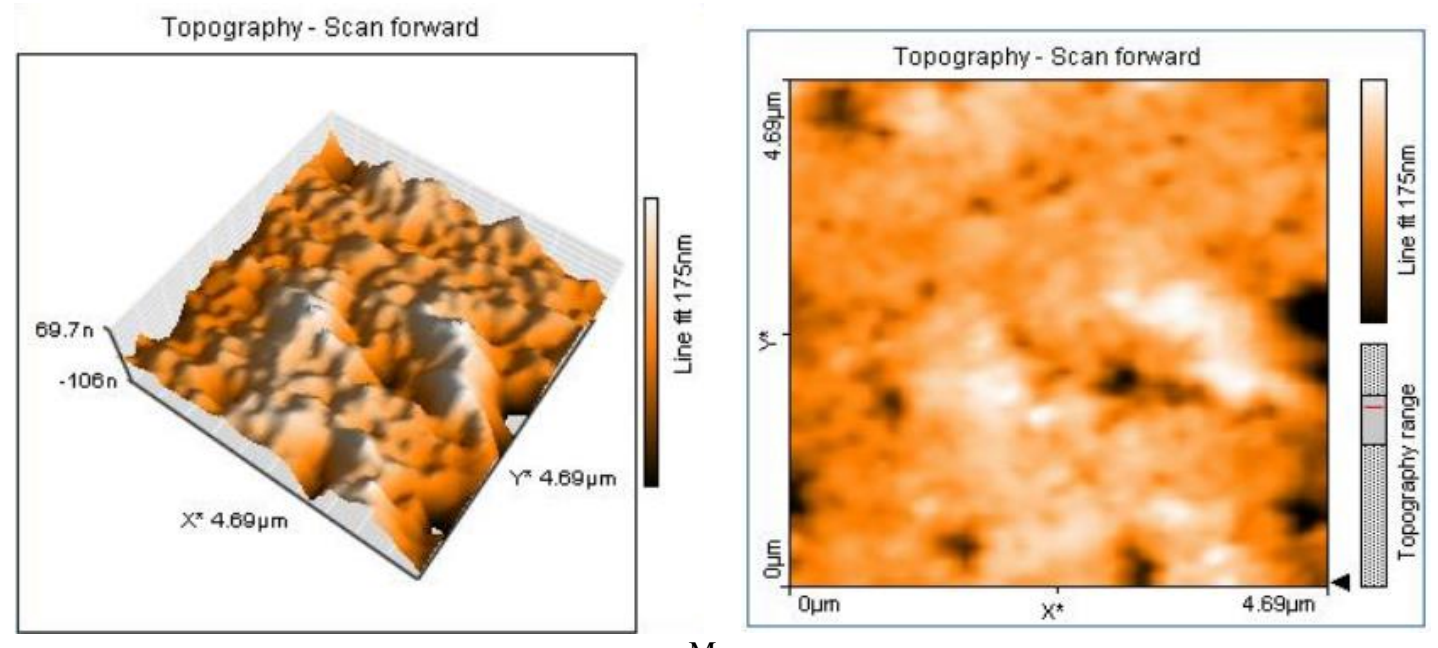

$\mathrm{M}_{1}$ 

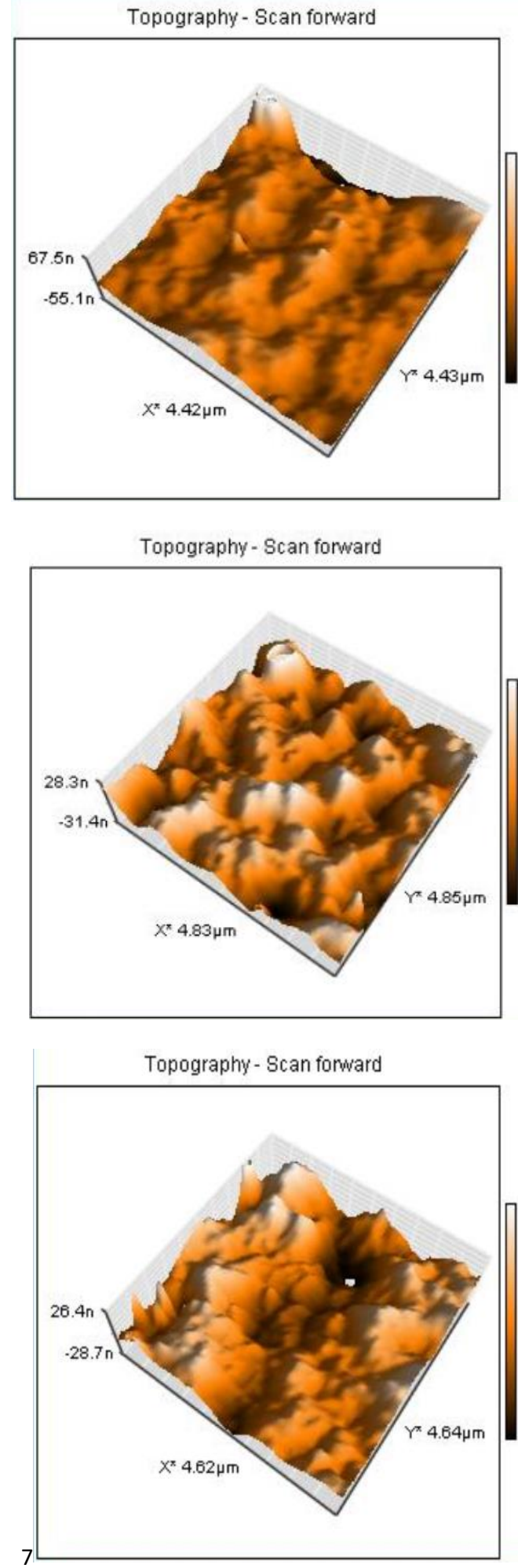

Fig. 11. 3D and 2D AFM images of the modified graphene oxide nanofiltration PES membranes ( $M_{1}=$ unfilled, $M_{2}=0.1$ wt. $\%, M_{3}=0.5$

\section{$\mathrm{M}_{4}$}

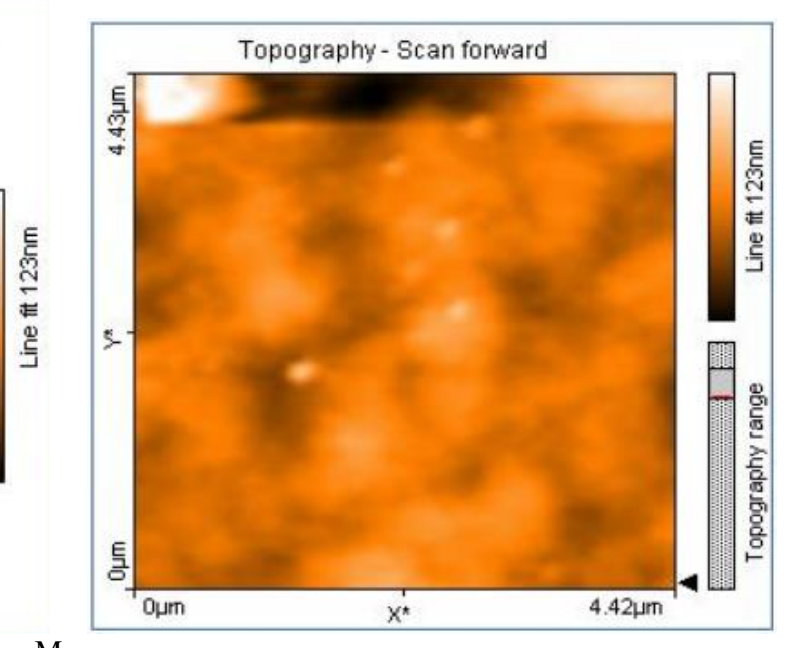

$\mathrm{M}_{2}$

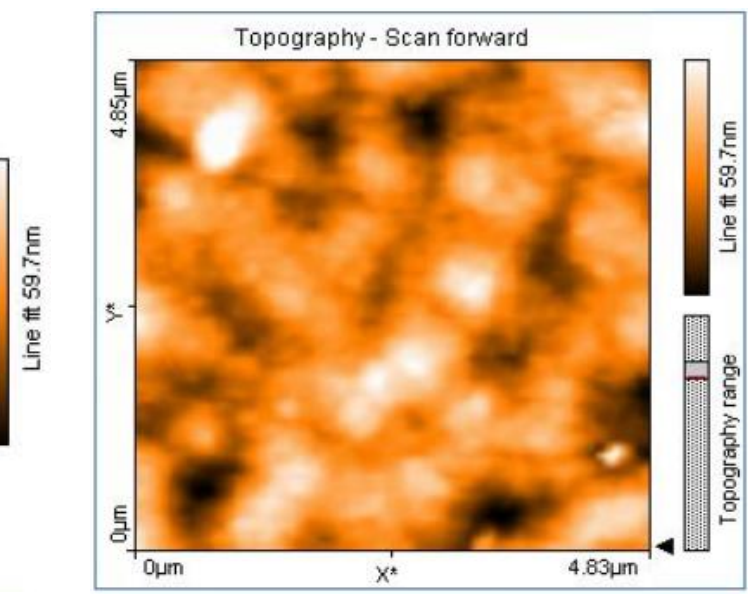

$\mathrm{M}_{3}$

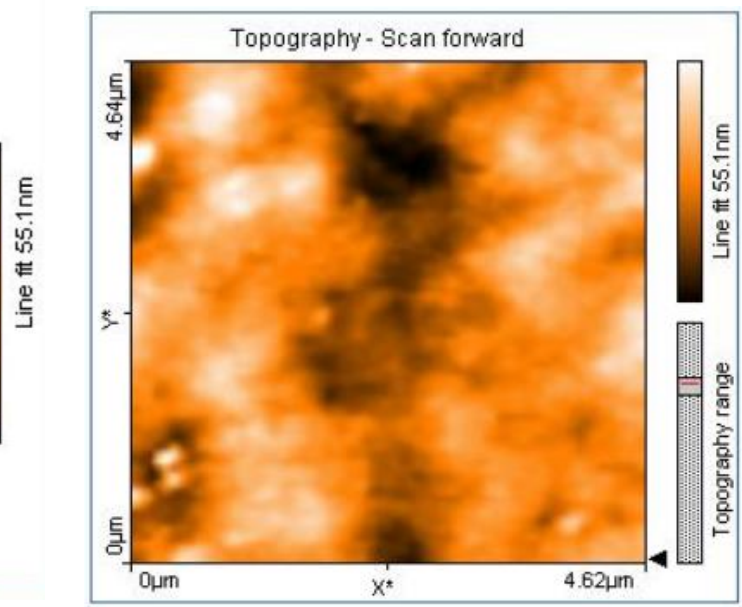

$\mathrm{M}_{4}$ wt. $\%$ and $\left.\mathrm{M}_{4}=1.0 \mathrm{wt} . \%\right)$. 
Table 4. Membrane surface roughness of modified graphene oxide filled nanofiltration PES membranes.

\begin{tabular}{cccc}
\hline Membrane & $\mathrm{S}_{\mathrm{a}}(\mathrm{nm})$ & $\mathrm{S}_{\mathrm{q}}(\mathrm{nm})$ & $\mathrm{S}_{\mathrm{z}}(\mathrm{nm})$ \\
\hline $\mathrm{M}_{1}$ & 21.251 & 28.671 & 245.15 \\
$\mathrm{M}_{2}$ & 8.003 & 10.014 & 67.483 \\
$\mathrm{M}_{3}$ & 8.755 & 11.363 & 103.83 \\
$\mathrm{M}_{4}$ & 9.707 & 14.705 & 162.8 \\
\hline
\end{tabular}

\subsection{Dye removal efficiency}

\subsubsection{Rejection and performance}

The dye rejection results are indicated in Fig. 12, that described the membrane capability for direct red 16 and methylene blue dye removal from simulated feed $(50 \mathrm{mg} / \mathrm{L})$ after $60 \mathrm{~min}$ filtration as a function of the modified graphene oxide percentage in the casting solution. The dye removal efficiency for the modified membrane $\left(\mathrm{M}_{2}\right)$ was achieved $99.58 \%$ and $97.98 \%$ for direct red 16 and methylene blue, respectively. Although the removal percentage for $\mathrm{M}_{1}$ is lower ( $87.5 \%$ and $83.29 \%$, respectively). This is caused by the presence of hydrophilic nanofiller in the membrane structures (Table 2) as an excellent refining agent [20]. This high removal percentage of colored materials can be attributed to two factors: I. chemical interactions (non-covalent bonds and $\pi-\pi$ stacking), II. electrostatic repulsion between color and membrane surface. In other words, because the direct red 16 and surface of the membrane both have a negative charge they repel each other (given the existence dispersion of negative groups at the matrix of the dye molecule, the direct red-16 indicates a negative nature at the neutral $\mathrm{pH}$ ), as well as non-covalent bonds (hydrogen bond) and $\pi-\pi$ stacking between the agents of direct red $16\left(-\mathrm{SO}_{3},-\mathrm{NH}_{2},-\mathrm{OH}\right.$ and aromatic rings) and distributed GO-CPTMS@Pd-TKHPP on the membrane surface, prevent passing of dye through the membrane and for these reasons that the removal efficiency was more than 99\% (Sabbatini et al. 2010, Zhang et al. 2019, Zhou et al. 2019). Although as shown in the Fig. 12 for methylene blue (aromatic rings $-\mathrm{N}$ and $-\mathrm{S}$ ), the removal percentage has decreased which caused the positive nature of the methylene blue and low molecular weight in methylene blue than direct red 16 (methylene blue and direct red 16 molecular weight: $319.85 \mathrm{~g} / \mathrm{mol}$ and $637.55 \mathrm{~g} / \mathrm{mol}$, respectively) so its possible methylene blue to pass through the membrane and results show the dye removal reduction for methylene blue than direct red 16 (Fig. 12). It should be noted that the permeation flux of dye solutions was slightly lower than the pure water flux, due to the adsorption of dye molecules on the membrane surface and the concentration polarization. According to the initial concentrations of direct red $16(50 \mathrm{mg} / \mathrm{L})$, the excellent rejection was obtained $99.58 \%$, but for precise evaluation of the dye rejection at a high concentration $(200 \mathrm{mg} / \mathrm{L})$, the dye rejection was also investigated that achieved 97.29\% (Bouazizi et al. 2017, Liu et al. 2017a) and also, in Table 6 comparison the performance of dye removal is provided. 


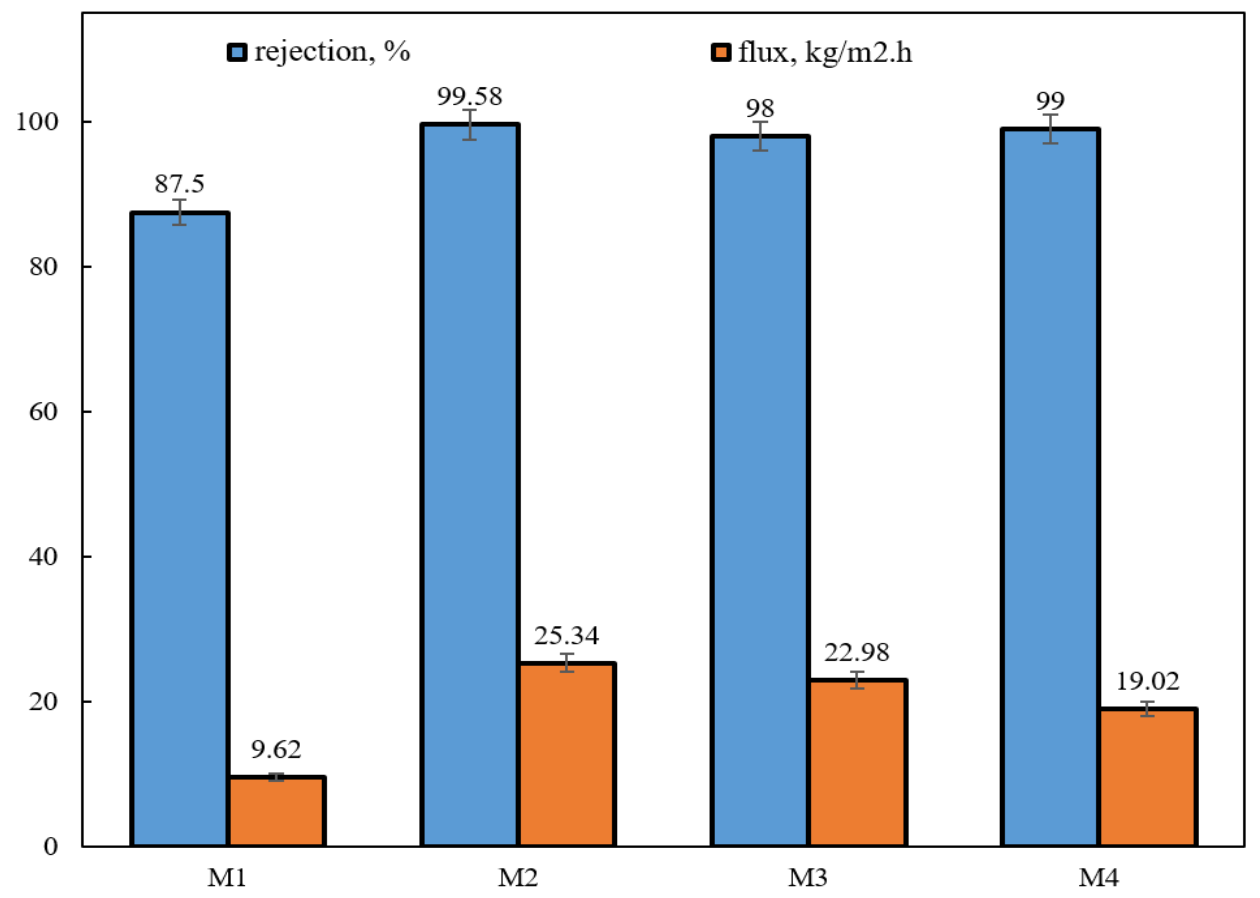

(a)

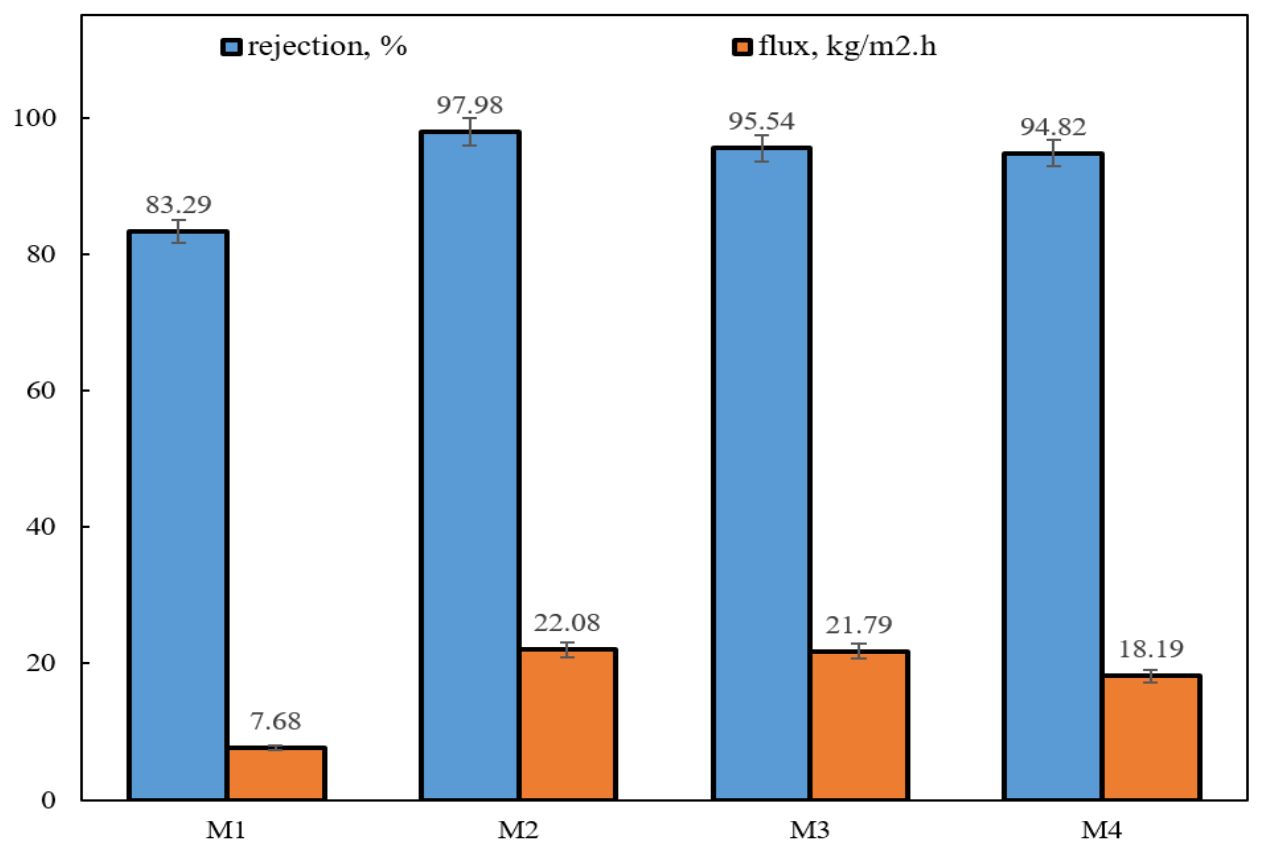

(b)

Fig. 12. Dye separation efficiency of modified graphene oxide-PES membranes, a) direct red 16 and b) methylene blue. 
Table 5. Comparison of dye separation performance of synthesized membranes with other works in literature.

\begin{tabular}{|c|c|c|c|c|c|c|}
\hline Membrane types & Dye types & $\begin{array}{c}\text { Molecular } \\
\text { weight, } \mathrm{g} / \mathrm{mol}\end{array}$ & $\begin{array}{c}\text { Dye concentration, } \\
\mathrm{mg} / \mathrm{l}\end{array}$ & $\begin{array}{c}\text { Dye } \\
\text { rejection, \% }\end{array}$ & $\begin{array}{l}\text { Dye flux, } \\
\mathrm{kg} / \mathrm{m}^{2} . \mathrm{h}\end{array}$ & Ref \\
\hline PSF/PEG/ZnCl ${ }_{2}$ & $\begin{array}{c}\text { Congo red } \\
\text { Crystal violet } \\
\text { Chrysoidine } \mathrm{R}\end{array}$ & $\begin{array}{l}696.65 \\
407.98 \\
262.74\end{array}$ & 200 & $\begin{array}{l}98 \\
98 \\
95\end{array}$ & $\begin{array}{c}10 \\
8 \\
10\end{array}$ & $\begin{array}{l}\text { (Panda \&De } \\
\text { 2014) }\end{array}$ \\
\hline PES/GO/TiO ${ }_{2}$ & $\begin{array}{l}\text { Reactive green } 19 \\
\text { Reactive blue } 21 \\
\text { Direct yellow } 12\end{array}$ & $\begin{array}{c}1418.93 \\
377.43 \\
1680.66\end{array}$ & 100 & $\begin{array}{c}99 \\
81.4 \\
95.4\end{array}$ & $\begin{array}{l}- \\
- \\
-\end{array}$ & $\begin{array}{l}\text { (Safarpour } \\
\text { et al. 2016) }\end{array}$ \\
\hline PES/ HNTs-SO ${ }_{3} \mathrm{H}$ & $\begin{array}{c}\text { Reactive black } 5 \\
\text { Reactive red } 49\end{array}$ & $\begin{array}{l}991.82 \\
576.49\end{array}$ & 1000 & $\begin{array}{c}90 \\
80-90\end{array}$ & - & $\begin{array}{l}\text { (Wang et al. } \\
\text { 2015) }\end{array}$ \\
\hline PES/CS/MMT & $\begin{array}{c}\text { Reactive black } 5 \\
\text { Reactive red } 49\end{array}$ & $\begin{array}{l}991.82 \\
576.49\end{array}$ & 500 & $\begin{array}{l}96 \\
93\end{array}$ & $\begin{array}{l}40 \\
40\end{array}$ & $\begin{array}{c}\text { (Zhu et al. } \\
\text { 2015) }\end{array}$ \\
\hline PES/Cellulose & $\begin{array}{l}\text { Direct red } 23 \\
\text { Direct red } 79\end{array}$ & $\begin{array}{c}813.73 \\
1048.87\end{array}$ & 1000 & $\begin{array}{l}98 \\
95\end{array}$ & $\begin{array}{l}- \\
-\end{array}$ & $\begin{array}{l}\text { (Lessan et } \\
\text { al. 2016) }\end{array}$ \\
\hline $\begin{array}{c}\text { PES/ GO- } \\
\text { CPTMS@Pd- } \\
\text { TKHPP }\end{array}$ & $\begin{array}{c}\text { Direct red } 19 \\
\text { Methylene blue }\end{array}$ & $\begin{array}{l}637.55 \\
319.85\end{array}$ & $\mathbf{5 0}$ & $\begin{array}{l}99.58 \\
97.98\end{array}$ & $\begin{array}{l}25.34 \\
22.08\end{array}$ & This work \\
\hline
\end{tabular}

\subsubsection{Long-term behavior}

317 The results of long term performance during the treatment of colored wastewater by the cross-flow system are

318 displayed in Table 6 and Fig. 13. From the results, due to the high cross-flow velocity (CFV) and hence the increase

319 of the Reynolds number (create turbulent flow due to Re>4000) so that, the cross-flow setup permeation showed

320 enhancement in compare with dead-end setup due to polarization concentration reduction (Bagheri et al. 2019).

Table 6. Long-term results for dye rejection.

\begin{tabular}{cccc}
\hline Membrane & Flux, $\mathrm{kg} / \mathrm{m}^{2} . \mathrm{h}$ & FRR, \% & Direct red-16 rejection, \% \\
\hline $\mathrm{M}_{1}$ & 15.29 & 68.42 & 89.61 \\
\hline $\mathrm{M}_{2}$ & 54.44 & 97.67 & 99.98 \\
\hline
\end{tabular}

321 According to Fig. 13 and Table 5, slump less flux in membrane permeability was observed in the prolonged dye 322 removal process. This phenomenon can be justified by reduction in the concentration polarization behind the 323 membrane during the examination process. The drop of the membrane flux at the $\mathrm{M}_{1}(31.58 \%$ reduction) is much 324 higher than that of the $\mathrm{M}_{2}$ (2.33\% reduction), which can be attributed to the membrane modification by the hydrophilic 325 nanoparticle and the donation of the anti-fouling property for $\mathrm{M}_{2}$ membrane. According to the results presented, it can 326 be obtained that the embedding of GO-CPTMS@Pd-TKHPP hydrophilic nanocomposite in the membrane matrix has 327 improved the performance of the color removal, flux enhancement and anti-fouling property (Zangeneh et al. 2019b). 


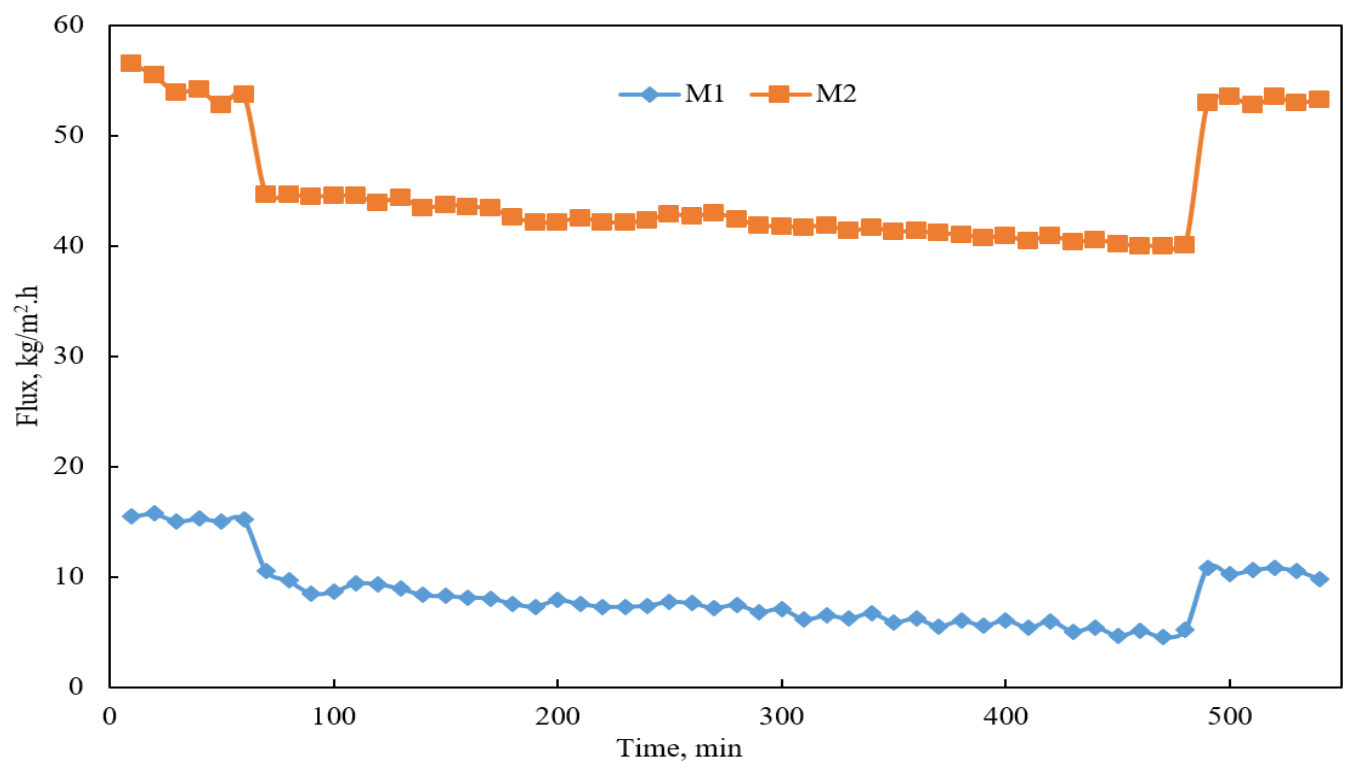

Fig. 13. Long-term filtration for dye removal ( $M_{1}=$ unfilled, $\left.M_{2}=0.1 w t . \%\right)$.

\section{Conclusion}

In this work, a hydrophilic nanofiller (modified graphene oxide nanocomposite) was successfully used and blende with the bare membrane during the phase inversion to reclaim membrane flux, antifouling and dye removal performance. The effect of modified graphene oxide in the casting solution was evaluated and chosen as the optimal membrane. The selected modified graphene oxide-PES membrane ( $0.1 \mathrm{wt} . \%$ of modified graphene oxide) exhibited better pure water flux $37.33 \mathrm{~kg} / \mathrm{m}^{2} . \mathrm{h}$ and dye rejection of $99.58 \%$ compared to the unmodified membranes. By embedding the modified graphene oxide, membrane hydrophilicity was significantly improved. Antifouling experiments showed that addition of the modified graphene oxide in the casting solution led to an increment in flux recovery ratio from $58.65 \%$ to $91.73 \%$ and a decrement in irreversible fouling from $41.35 \%$ to $8.24 \%$. The result of long filtration in the cross-flow system revealed that the optimized membrane can be proposed for industrial wastewater treatment.

\section{-Ethical Approval}

Not applicable

\section{-Consent to Participate}

Not applicable

\section{-Consent to Publish}

Not applicable

\section{-Authors Contributions}

Foad Gholami: Conceptualization, Data curation, Formal analysis, Writing - original draft

Sirus Zinadini: Funding acquisition, Project administration,

Soheila Nakhjiri Kamrani: Investigation

Ali Akbar Zinatizadeh: Supervision, Writing - review \& editing 
Kiumars Bahrami, Writing - review \& editing, Supervision

\section{-Competing Interests}

352 The authors declare that they have no competing interests.

\section{-Funding}

354 No sources of funding for the research study.

\section{5 -Availability of data and materials}

356 The datasets used and/or analyzed during the current study are available from the corresponding author on reasonable 357 request.

\section{References:}

Abdi G, Alizadeh A, Zinadini S, Moradi G (2018): Removal of dye and heavy metal ion using a novel synthetic polyethersulfone nanofiltration membrane modified by magnetic graphene oxide/metformin hybrid. Journal of membrane science 552, 326-335

Ang WL, Mohammad AW, Hilal N, Leo CP (2015): A review on the applicability of integrated/hybrid membrane processes in water treatment and desalination plants. Desalination 363, 2-18

Ayyaru S, Ahn Y-H (2017): Application of sulfonic acid group functionalized graphene oxide to improve hydrophilicity, permeability, and antifouling of PVDF nanocomposite ultrafiltration membranes. Journal of membrane science 525, 210-219

Bagheri M, Akbari A, Mirbagheri SA (2019): Advanced control of membrane fouling in filtration systems using artificial intelligence and machine learning techniques: A critical review. Process Safety and Environmental Protection 123, 229-252

Bahrami K, Kamrani SN (2018): Synthesis, characterization and application of graphene palladium porphyrin as a nanocatalyst for the coupling reactions such as: Suzuki-Miyaura and Mizoroki-Heck. Applied Organometallic Chemistry 32, e4102

Bouazizi A, Breida M, Achiou B, Ouammou M, Calvo JI, Aaddane A, Younssi SA (2017): Removal of dyes by a new nano-TiO2 ultrafiltration membrane deposited on low-cost support prepared from natural Moroccan bentonite. Applied clay science 149, 127-135

Chen J-L, Yan X-P (2010): A dehydration and stabilizer-free approach to production of stable water dispersions of graphene nanosheets. Journal of Materials Chemistry 20, 4328-4332

Cote LJ, Kim J, Zhang Z, Sun C, Huang J (2010): Tunable assembly of graphene oxide surfactant sheets: wrinkles, overlaps and impacts on thin film properties. Soft Matter 6, 6096-6101

Deka JR, Liu C-L, Wang T-H, Chang W-C, Kao H-M (2014): Synthesis of highly phosphonic acid functionalized benzene-bridged periodic mesoporous organosilicas for use as efficient dye adsorbents. Journal of hazardous materials $278,539-550$

Ding S, Zhang L, Li Y, Hou L-a (2019): Fabrication of a novel polyvinylidene fluoride membrane via binding SiO2 nanoparticles and a copper ferrocyanide layer onto a membrane surface for selective removal of cesium. Journal of hazardous materials 368, 292-299 
Elimelech M, Phillip WA (2011): The future of seawater desalination: energy, technology, and the environment. Science 333, 712-717

Emam HE, Abdelhamid AE, Abdelhameed RM (2019): Refining of liquid fuel from N-Containing compounds via using designed Polysulfone@ Metal organic framework composite film .Journal of cleaner production 218, $347-356$

Fareghi-Alamdari R, Golestanzadeh M, Bagheri O (2016): meso-Tetrakis [4-(methoxycarbonyl) phenyl] porphyrinatopalladium (II) supported on graphene oxide nanosheets (Pd (II)-TMCPP-GO): synthesis and catalytic activity. RSC Advances 6, 108755-108767

Fathizadeh M, Xu WL, Zhou F, Yoon Y, Yu M (2017): Graphene oxide: a novel 2-dimensional material in membrane separation for water purification. Advanced Materials Interfaces 4, 1600918

Gholami F, Zinadini S, Zinatizadeh A, Noori E, Rafiee E (2017): Preparation and characterization of an antifouling polyethersulfone nanofiltration membrane blended with graphene oxide/Ag nanoparticles. Int. J. Eng. Trans. A Basics 30, 1425-1433

Hairom NHH, Mohammad AW, Kadhum AAH (2014) :Nanofiltration of hazardous Congo red dye: performance and flux decline analysis. Journal of Water Process Engineering 4, 99-106

Hegab HM, Zou L (2015): Graphene oxide-assisted membranes: fabrication and potential applications in desalination and water purification. Journal of Membrane Science 484, 95-106

Hu M, Zheng S, Mi B (2016): Organic fouling of graphene oxide membranes and its implications for membrane fouling control in engineered osmosis. Environmental science \& technology 50, 685-693

Hua Z, Tang Z, Bai X, Zhang J, Yu L, Cheng H (2015): Aggregation and resuspension of graphene oxide in simulated natural surface aquatic environments. Environmental pollution 205, 161-169

Huang A, Liu Q, Wang N, Zhu Y, Caro Jr (2014): Bicontinuous zeolitic imidazolate framework ZIF-8@ GO membrane with enhanced hydrogen selectivity. Journal of the American Chemical Society 136, 14686-14689

Huang H, Song Z, Wei N, Shi L, Mao Y, Ying Y, Sun L, Xu Z, Peng X (2013): Ultrafast viscous water flow through nanostrand-channelled graphene oxide membranes. Nature communications 4, 2979

Januário EFD, Beluci NdCL, Vidovix TB, Vieira MF, Bergamasco R, Vieira AMS (2020): Functionalization of membrane surface by layer-by-layer self-assembly method for dyes removal. Process Safety and Environmental Protection 134, 140-148

Koltonow AR, Huang J (2016): Two-dimensional nanofluidics. Science 351, 1395-1396

Lee N, Amy G, Croue J-P, Buisson H (2004): Identification and understanding of fouling in low-pressure membrane (MF/UF) filtration by natural organic matter (NOM). Water research 38, 4511-4523

Lessan F, Karimi M, Arami M (2016): Tailoring the hierarchical porous structure within polyethersulfone/cellulose nanosheets mixed matrix membrane to achieve efficient dye/salt mixture fractionation. Journal of Polymer Research 23, 171

Li R, Ren Y, Zhao P, Wang J, Liu J, Zhang Y (2019): Graphitic carbon nitride (g-C3N4) nanosheets functionalized composite membrane with self-cleaning and antibacterial performance. Journal of hazardous materials 365 , 606-614 
Liu C, Mao H, Zheng J, Zhang S (2017a): Tight ultrafiltration membrane: Preparation and characterization of thermally resistant carboxylated cardo poly (arylene ether ketone) s (PAEK-COOH) tight ultrafiltration membrane for dye removal. Journal of Membrane Science 530, 1-10

Liu G, Han K, Ye H, Zhu C, Gao Y, Liu Y, Zhou Y (2017b): Graphene oxide/triethanolamine modified titanate nanowires as photocatalytic membrane for water treatment. Chemical Engineering Journal 320, 74-80

Mahmodi G, Dangwal S, Zarrintaj P, Zhu M, Mao Y, Mcllroy DN, Saeb MR, Vatanpour V, Ramsey JD, Kim S-J (2020a): NaA Zeolite-Coated Meshes with Tunable Hydrophilicity for Oil-Water Separation. Separation and Purification Technology, 116630

Mahmodi G, Zarrintaj P, Taghizadeh A, Taghizadeh M, Manouchehri S, Dangwal S, Anil R, Ganjali MR, Ramsey JD, Kim S-J (2020b): From microporous to mesoporous mineral frameworks: An alliance between zeolite and chitosan. Carbohydrate Research, 107930

Manda BK, Worrell E, Patel MK (2014): Innovative membrane filtration system for micropollutant removal from drinking water-prospective environmental LCA and its integration in business decisions. Journal of cleaner production 72, 153-166

Modi A, Bellare J (2019): Efficient removal of dyes from water by high flux and superior antifouling polyethersulfone hollow fiber membranes modified with $\mathrm{ZnO} / \mathrm{cGO}$ nanohybrid. Journal of Water Process Engineering 29, 100783

Moradi G, Zinadini S, Rajabi L (2020): Development of high flux nanofiltration membrane using para-amino benzoate ferroxane nanoparticle for enhanced antifouling behavior and dye removal. Process Safety and Environmental Protection 144, 65-78

Mukherjee R, Bhunia P, De S (2019): Nanofiltration range desalination by high flux graphene oxide impregnated ultrafiltration hollow fiber mixed matrix membrane. Journal of cleaner production 213, 393-405

Ng LY, Mohammad AW, Leo CP, Hilal N (2013): Polymeric membranes incorporated with metal/metal oxide nanoparticles: a comprehensive review. Desalination $308,15-33$

Panda SR, De S (2014): Preparation, characterization and performance of $\mathrm{ZnCl} 2$ incorporated polysulfone (PSF)/polyethylene glycol (PEG) blend low pressure nanofiltration membranes. Desalination 347, 52-65

Papageorgiou DG, Kinloch IA, Young RJ (2015) :Graphene/elastomer nanocomposites. Carbon 95, 460-484

Pirsaheb M, Farahani MHDA, Zinadini S, Zinatizadeh AA, Rahimi M, Vatanpour V (2019): Fabrication of highperformance antibiofouling ultrafiltration membranes with potential application in membrane bioreactors (MBRs) comprising polyethersulfone (PES) and polycitrate-Alumoxane (PC-A). Separation and Purification Technology 211, 618-627

Qian Y, Zhou C, Huang A (2018): Cross-linking modification with diamine monomers to enhance desalination performance of graphene oxide membranes. Carbon 136, 28-37

Sabbatini P, Yrazu F, Rossi F, Thern G, Marajofsky A, de Cortalezzi MF (2010): Fabrication and characterization of iron oxide ceramic membranes for arsenic removal. Water research 44, 5702-5712

Safarpour M ,Vatanpour V, Khataee A (2016): Preparation and characterization of graphene oxide/TiO2 blended PES nanofiltration membrane with improved antifouling and separation performance. Desalination 393, 65-78 
Song Y, Sun Y, Chen M, Huang P, Li T, Zhang X, Jiang K (2020): Efficient removal and fouling-resistant of anionic dyes by nanofiltration membrane with phosphorylated chitosan modified graphene oxide nanosheets incorporated selective layer. Journal of Water Process Engineering 34, 101086

Vatanpour V, Madaeni SS, Moradian R, Zinadini S, Astinchap B (2011): Fabrication and characterization of novel antifouling nanofiltration membrane prepared from oxidized multiwalled carbon nanotube/polyethersulfone nanocomposite. Journal of Membrane Science 375, 284-294

Wang H-W, Hu Z-A, Chang Y-Q, Chen Y-L, Zhang Z-Y, Yang Y-Y, Wu H-Y (2011): Preparation of reduced graphene oxide/cobalt oxide composites and their enhanced capacitive behaviors by homogeneous incorporation of reduced graphene oxide sheets in cobalt oxide matrix. Materials Chemistry and Physics 130, $672-679$

Wang Y, Zhu J, Dong G, Zhang Y, Guo N, Liu J (2015): Sulfonated halloysite nanotubes/polyethersulfone nanocomposite membrane for efficient dye purification. Separation and Purification Technology 150, 243251

Warsinger DM, Chakraborty S, Tow EW, Plumlee MH, Bellona C, Loutatidou S, Karimi L, Mikelonis AM, Achilli A, Ghassemi A (2018): A review of polymeric membranes and processes for potable water reuse. Progress in polymer science $81,209-237$

You S-J, Semblante GU, Lu S-C, Damodar RA, Wei T-C (2012): Evaluation of the antifouling and photocatalytic properties of poly (vinylidene fluoride) plasma-grafted poly (acrylic acid) membrane with self-assembled TiO2. Journal of hazardous materials 237, 10-19

Yuan X-T, Xu C-X, Geng H-Z, Ji Q, Wang L, He B, Jiang Y, Kong J, Li J (2020): Multifunctional PVDF/CNT/GO mixed matrix membranes for ultrafiltration and fouling detection. Journal of hazardous materials 384, 120978

Zaaba N, Foo K, Hashim U, Tan S, Liu W-W, Voon C (2017): Synthesis of graphene oxide using modified hummers method: solvent influence. Procedia engineering 184, 469-477

Zangeneh H, Zinatizadeh AA, Zinadini S, Feyzi M, Bahnemann DW (2019a): Preparation and characterization of a novel photocatalytic self-cleaning PES nanofiltration membrane by embedding a visible-driven photocatalyst boron doped-TiO2SiO2/CoFe2O4 nanoparticles. Separation and Purification Technology 209, 764-775

Zangeneh H, Zinatizadeh AA, Zinadini S, Feyzi M, Bahnemann DW (2019b): Preparation ultrafine L-Methionine (C, $\mathrm{N}, \mathrm{S}$ triple doped)-TiO2-ZnO nanoparticles and their photocatalytic performance for fouling alleviation in PES nanocomposite membrane. Composites Part B: Engineering 176, 107158

Zhang J, Feng A, Bai J, Tan Z, Shao W, Yang Y, Hong W, Xiao Z (2017): One-pot synthesis of hierarchical flowerlike Pd-Cu alloy support on graphene towards ethanol oxidation. Nanoscale research letters 12, 521

Zhang X, Li H, Wang J, Peng D, Liu J, Zhang Y (2019): In-situ grown covalent organic framework nanosheets on graphene for membrane-based dye/salt separation. Journal of Membrane Science 581, 321-330

Zhou M-Y, Zhang P, Fang L-F, Zhu B-K, Wang J-L, Chen J-H, Abdallah HM (2019): A positively charged tight UF membrane and its properties for removing trace metal cations via electrostatic repulsion mechanism. Journal of hazardous materials $373,168-175$ 
501

502

Zhu J, Tian M, Zhang Y, Zhang H, Liu J (2015): Fabrication of a novel "loose" nanofiltration membrane by facile blending with Chitosan-Montmorillonite nanosheets for dyes purification. Chemical Engineering Journal 265, 184-193

Zinadini S, Zinatizadeh AA, Rahimi M, Vatanpour V, Zangeneh H (2014): Preparation of a novel antifouling mixed matrix PES membrane by embedding graphene oxide nanoplates. Journal of Membrane Science 453, 292301

Zolfigol MA, Khakyzadeh V, Moosavi-Zare AR, Rostami A, Zare A, Iranpoor N, Beyzavi MH, Luque R (2013): A highly stable and active magnetically separable Pd nanocatalyst in aqueous phase heterogeneously catalyzed couplings. Green Chemistry 15, 2132-2140

\section{Declaration of interests}

$\bigotimes$ The authors declare that they have no known competing financial interests or personal relationships that could have appeared to influence the work reported in this paper.

$\square$ The authors declare the following financial interests/personal relationships which may be considered as potential competing interests:

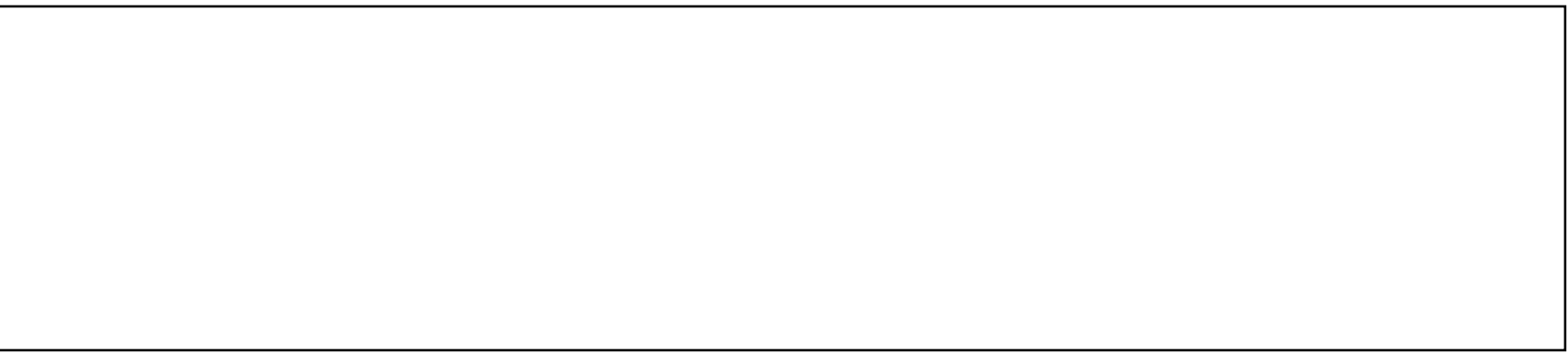

